\title{
Convivial Ambient Technologies: Requirements, Ontology and Design
}

\author{
PATRICE CAIRE* AND LEENDERT VAN DER TORRE \\ Faculty of Sciences, Technology and Communication, University of Luxembourg, 6, rue Richard \\ Coudenhove-Kalergi L-1359, Luxembourg city, Luxembourg \\ ${ }^{*}$ Corresponding author: patrice.caire@uni.lu
}

\begin{abstract}
In this paper we discuss the use of the social concept 'conviviality' for computer science in general, and for the development of ambient technologies in particular. First, we give a survey of the use of the concept 'conviviality' in the social sciences. Conviviality is usually considered a positive concept related to sociability. However, further analysis reveals a negative side related to lack of diversity, privacy and ethical issues. Second, we argue that conviviality requirements for ambient intelligence are challenging, because ambient technologies give rise to a new virtual and social reality, and conviviality issues play a central role in applications that are concerned with the interaction of material, virtual and social realities. Conviviality highlights an important challenge that we illustrate with examples that emphasize ethical issues, such as privacy threats, surveillance of users and identity theft. Intelligent interfaces, for example, allow instant interactions and thereby create strong needs for coordination and regulation mechanisms that have to be addressed to ensure the safeguard of individuals against abuses, such as privacy intrusions and identity manipulations. Third, we propose a conviviality ontology by operationalizing the fuzzy concept of 'conviviality', such that it can be used in computer science in the same way as other social concepts such as 'service,' 'contract' or 'trust' are used in this area. Conviviality is defined using dependence networks, and tools for conviviality are based on, what we call, conviviality masks. Fourth, we illustrate how convivial ambient intelligence applications can be designed using our operationalized concept of conviviality. We illustrate our arguments and contributions with a running example on the use of ambient technologies in digital cities, as a prototypical example where material reality such as ambient technologies interacts with virtual and social realities.
\end{abstract}

Keywords: ambient intelligence; conviviality; norms; agents

Received 26 February 2008; revised 2 February 2009

Handling editors: Fariba Sadri and Kostas Stathis

\section{INTRODUCTION}

The term ambient intelligence, used in 1999 by the European Union's Information Society Technologies Program Advisory Group (ISTAG) [1], describes a vision where 'people will be surrounded by intelligent and intuitive interfaces embedded in everyday objects around us and an environment recognizing and responding to the presence of individuals in an invisible way.' Ambient technologies rely upon transparent, unobtrusive and intuitive interfaces, closer to the way people think and feel than to the way machines operate.

Ambient technologies aim to make computer systems more adapted to human needs. One of the goals of ambient intelligence is to give individuals the possibility to express themselves more efficiently, accurately and effortlessly [2], by invisibly capturing and tracking their preferences into profiles [3]. Hence, the need for context aware applications to take into consideration notions such as privacy, identity and social concepts such as trust $[4,5]$.

In the 1990s, user-friendliness had become ubiquitous in software development. Human computer interfaces, that had championed the concept, was elevated to a taught discipline and a research field concerned with the design, evaluation and implementation of interactive computing systems for human use. The key idea was to create a pleasant, helpful and friendly experience for humans accomplishing computer tasks. Design methodologies used heuristics and the guideline, measurements were usability metrics such as navigation, page load speed, accessibility and content relevance. Since then, the rapid 


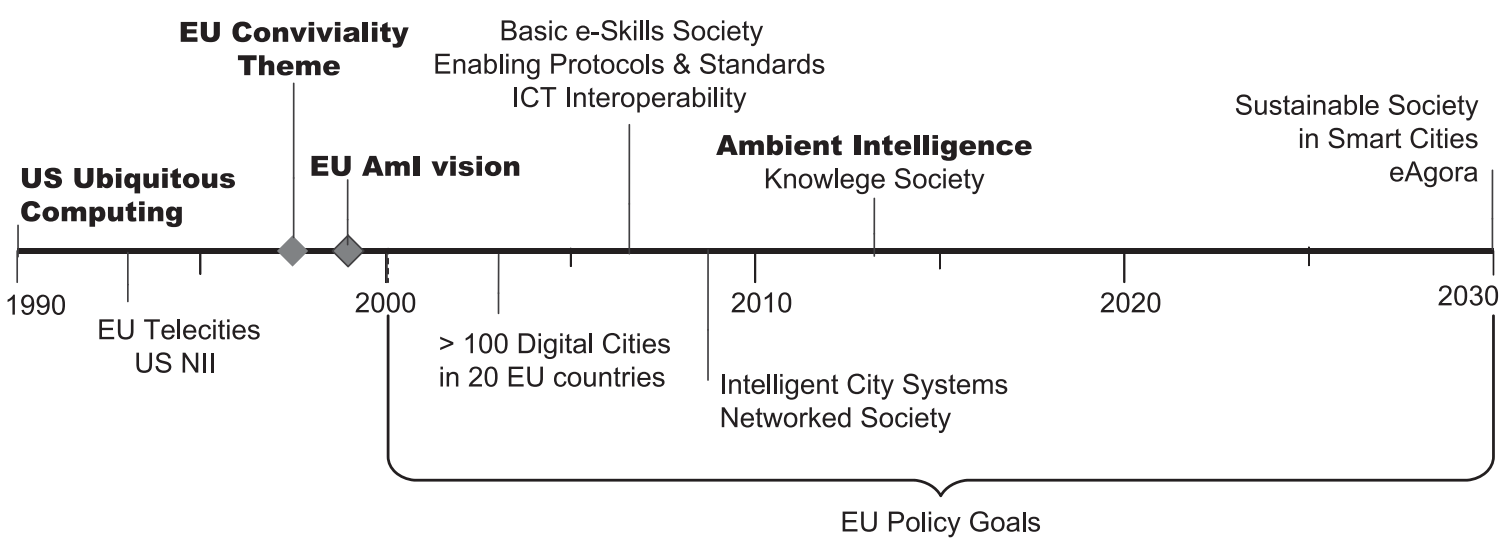

FIGURE 1. Time line for the correlated development of ambient intelligence, the EU digital cities programs, and the conviviality theme.

development and pervasiveness of games, social software and networks has highlighted the need for dynamic interpersonal communication and social interactions.

The concept that encapsulates these ideas is conviviality. If user-friendliness is indeed mandatory for software usability and accessibility, it is conviviality alone that can convey the social complexity that today's technology is striving for. But what is really at stake? In this political context, the EU launched a spearhead research theme, from 1998 to 2002, called 'société de l'information conviviale' (Fig. 1), more commonly known as the 'Information Society Technologies programme.' The purpose of this program was to promote user empowerment through accessibility of information to all, with increased security, and in the context of wider development of ambient intelligence and distributed systems. Unfortunately, the English translation of 'société de l'information conviviale' replaced 'convivial' with the expression 'user-friendly.' How far is this a mistranslation? Does user-friendliness really convey what is inherent in conviviality?

This question of conviviality has recently become part of a debate which remains unquelled; yet what is conviviality? Could it simply be creating a cordial atmosphere at a dinner party or good relations between friends (Fig. 2)? Is it a prism which refracts the pressures of modern society? It has even burst onto the public scene through politicians' speeches. Discussions on conviviality have fanned the flames of debates: Should conviviality be used to regulate how citizens interact, to create stronger ties between them? Make them more dependent on each other? Should it be used as a tool to manipulate citizens? This is all overstated. What is however now undisputed is that there is more to conviviality than once thought.

In previous work, we identify conviviality as a key concept necessary to web communities, such as digital cities [6]. While it has been simultaneously defined in the literature as 'individual freedom realized in personal interdependence,' 'rational and cooperative behavior' and 'a normative instrument,' as we discuss in Section 4, no model for conviviality has yet been

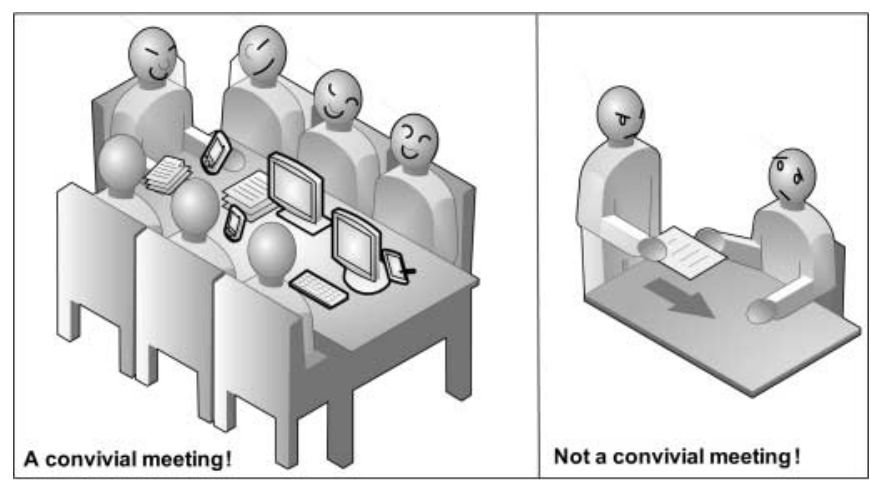

(a)

(b)

FIGURE 2. (a) Everyone feels at ease, dependencies are reciprocal. (b) Not convivial one-way dependencies.

proposed for computer science. In [6], we raise the question whether social intelligence design could be used to designing convivial digital cities. We first look at digital cities and identify, from the point of view of a social intelligence design two main categories of digital cities: public web sites and commercial web sites; we also note the experimental qualities of digital cities. Second, in [6] we analyze the concept of conviviality for social science, multiagent systems (MAS) and intelligent interface; we show the distinction among various kinds of use of conviviality, the positive outcomes such as social cohesion, trust and participation but also the negative aspects that emerged when conviviality became an instrument of power relations. Third, we look at the normative aspect of conviviality as described in the literature and find that social norms for conviviality parallel legal and institutional norms for digital cities. Finally, as an initial step towards obtaining measures for conviviality, we present a case study describing interactions between agents and user using dependence graphs. We also present an analysis of conviviality requirements and describe a plan and methodology for designing convivial digital 
cities. Moreover, in [7] we import the concept of conviviality to web communities by raising the question of what is distinct in computer science and what is the challenge of conviviality in computer science.

In this paper, we further develop this vision. We are interested in the following research question:

How to use the social concept of 'conviviality' to develop userfriendly ambient intelligence applications?

To make this paper self-contained, we also summarize and reconsider some of the issues discussed in [6,7]. Our overall research question therefore breaks down into the following research questions:

(i) What is conviviality? What kinds of conviviality exist?

(ii) Which conviviality requirements are relevant for computer science in general and ambient intelligence in particular? Which issues are relevant when developing convivial ambient intelligence?

(iii) Which conviviality ontology should we use for ambient intelligence?

(iv) How to design convivial ambient intelligence applications? How can the positive aspects of conviviality be used for ambient intelligence? How should the negative aspects of conviviality be taken into account?

To ground our use of conviviality in computer science, we have to understand the range of meanings and uses of the concept 'conviviality' in the social sciences, and we therefore start with a literature survey. We distinguish between kinds of conviviality by distinguishing positive and negative aspects of the concept. Conviviality is usually considered a positive concept related to sociability, however, further analysis reveals a negative side related to ethical issues.

To study the relevance of conviviality requirements, we first ask why applications should be user-friendly or convivial, and then we ask why the concept should be used to develop ambient intelligence applications. We argue that conviviality requirements for ambient intelligence are challenging, because ambient intelligence artifacts give rise to a new virtual and social reality, and conviviality issues play a central role in applications that are concerned with the interaction of material, virtual and social realities. Conviviality highlights an important challenge that we illustrate with examples that emphasize ethical issues, such as privacy threats, surveillance of users and identity theft. Intelligent interfaces, for example, allow instant interactions and thereby create strong needs for coordination and regulation mechanisms that have to be addressed to ensure the safeguard of individuals against abuses, such as privacy intrusions and identity manipulations.

To define a conviviality ontology and operationalize the concept of 'conviviality,' we relate the concept of 'conviviality' to concepts of 'dependence.' We propose a conviviality ontology by operationalizing the fuzzy concept of 'conviviality', such that it can be used in computer science in the same way as other social concepts like 'service,' 'contract' or 'trust' are used. Conviviality is defined using dependence networks, and tools for conviviality are based on, what we call, conviviality masks. To define tools for conviviality, we define conviviality masks as a transformation of social dependencies by hiding power relations and social structures to facilitate social interactions. We propose a design methodology to design convivial ambient intelligence applications using our operationalized concept of conviviality.

We consider our research questions answered when we have convinced developers of ambient technologies that conviviality may be a useful concept for ambient intelligence, which can be operationalized in requirement analysis, used in modeling languages and applied in design. However, we do not consider the validation of our approach in this paper, but leave it to further research. This paper is best seen as a proposal for a research program consisting of the development of languages for requirements analysis, languages for ontologies and methodologies for design. However, since we aim to convince technology developers, this does not mean that we restrict ourselves to an abstract conceptual or philosophical analysis, but we make our proposal concrete and illustrate it with a futuristic but realistic example.

We illustrate our arguments and contributions with a running example on the use of ambient technologies in digital cities, as a prototypical example where material reality such as ambient technologies interact with virtual and social realities. For example, in a digital city that integrates the virtual world with the real world, people may walk around in the real city with PDAs and leave notes in the virtual world. Many if not all future application use-cases are a combination of the real and virtual world. For example, besides leaving notes about the real world in the virtual world, people now use real money to buy property in Second Life (SL), and real university lectures are given in SL. Therefore, we use the digital city example as a paradigmatic example for these future use-cases.

Our motivation is the 'Inventing Communities of Communication' project (ICC) initiated by the University of Luxembourg in April 2006. The City of Luxembourg acting as a co-partner provides us with use-cases and is a test bed for our research. The city project is to transform its current city web site into a centralized online administration, the e-City, fully integrated with eLuxembourg, the state portal. City goals are: provide citizens and visitors with electronic services to communicate with their administration while giving online access to solve administrative requests, such as change of address and formal documents surrounding child birth. The development of such digital cities is part of the eEurope strategy as first defined in Lisbon in 2000.

The layout of this paper is as follows. In Section 2 we address the use of social concepts in computer science. In Section 3 we introduce the running example of ambient intelligence in digital cities. In Section 4 we present a historical overview on the concept 'conviviality.' In Section 5 we discuss the relevance of the concept for requirements for computer science systems in 
general, and ambient intelligence applications in particular. In Section 6 we discuss which definition of conviviality can be used and operationalized in ontologies to model ambient intelligence applications, and in particular how the concept of conviviality is related to other concepts. In Section 7 we consider the design of convivial ambient intelligence applications.

\section{SOCIAL CONCEPTS IN COMPUTER SCIENCE}

A social concept like 'conviviality' can be used in ambient intelligence in various ways. Consider the following examples:

Informal requirements of decision makers: 'our system should be convivial and easy to use'; of users: 'I want to interact with a convivial system populated by other users who make me feel welcome.'

Formal concept in an ontology for modeling ambient systems: 'system A is convivial whereas system B is efficient.'

Performance measures: 'the conviviality is 87 on a scale from 0 to 100 .'

Programming constructs: 'if use $<10$, then conviviality ++ .'

Though the latter ones may seem farfetched at the moment, many other social concepts have been adopted by computer science at all these different levels, from concepts in informal requirements via modeling concepts in UML to programming constructs. For example, mainstream computer science nowadays involves social concepts like 'services,' 'contracts' and 'coordination' at all of these levels. Some of these social concepts have been adopted by ambient intelligence too, though this area seems to be suited for other social concepts from the mainstream ones.

In this section we give some examples of existing social concepts in computer science to study the kind of applications we may consider for the conviviality concept in ambient intelligence. We do not attempt to be complete.

\subsection{Business informatics}

Business informatics is an interdisciplinary discipline using many concepts from other disciplines. For example, 'architecture' is defined as the fundamental organization of a system embodied in its components, their relationships to each other and to the environment, and the principles guiding its design and evolution. The recent standard called IEEE 1471-2000 [8] emphasizes that views on the architecture should always be considered in the context of the viewpoint of a stakeholder (e.g. software engineer, business manager) with a particular concern (e.g. security). A system is a collection of components organized to accomplish a specific function or set of functions. A system's stakeholder is an individual, team or organization (or classes thereof) with interests in, or concerns relative to, a system. A view is a representation of a whole system from the perspective of a related set of concerns. A viewpoint is a specification of the conventions for constructing and using a view; it is a pattern or template from which to develop individual views by establishing the purposes and audience for a view and the techniques for its creation and analysis.

Another example is the term 'value.' In economics 'values' are related to the preferences of a decision maker. Value networks model the creation, distribution, and consumption of economic value in a network of multiple enterprises and end-consumers. This leads to the definition of obligations of the actors and ways to deal with violations, to ensure that actors behave according to the value network model. Finally, control procedures and protocols are added to ensure that obligations are fulfilled or violations sanctioned. Note that these issues appear to be different from traditional issues studied in computer security, such as cryptography. Also traditional formalisms of, for example, authorization and authentification, such as the popular BAN logics [9], focus on issues such as public key infrastructures instead of formal models of contracts.

The concept of 'privacy' and data protection are viewed as complementary and interdependent. Both tend to preserve individuals from excessive constraints and influences. Different facets of personal privacy can be distinguished depending on motives and ambient intelligence technologies' two important parameters relating to privacy: the ability to monitor, e.g. surveillance, and the power to search and combine information bits [10]. In the ambient intelligence context, techniques devised for privacy protection policies must be flexible. Three main requirements have been identified to reach this goal: formal specification of privacy policies, trust management and auditability, e.g. a posteriori measures [11].

\subsection{MAS}

Another interdisciplinary area is MAS. Concepts, models and theories from the social sciences are studied in MAS to regulate or control interactions among agents [12], as a theoretical basis for the development of so-called social software [13], and to develop MAS for computational social science [14]. Examples of social concepts studied in MAS are societies, coalitions, organizations, institutions, norms, power, and trust [15].

Considering the notion of 'dependencies,' it is noted that values and preferences lead to dependencies among actors, when the actors have limited or bounded resources. For example, dependencies among enterprises explain why and how they create, distribute and consume economic value. This leads to a second topology: besides the topology of the network over which values are exchanged, there is also the topology of the dependency network. The value network and the dependency network are clearly related, as value exchanges are motivated by dependencies, and change the dependencies. 


\subsection{Service-oriented computing}

'Service' is a concept from business economics, which has been used in computer science in service-oriented architectures and in web services. Not only business processes but also computer applications are modeled as service providers. An advantage of services is that complex services can be offered as a bundle of simpler services. For example, the service of a travel agency to organize a holiday trip may consist of services to book a flight, and make reservations for a hotel and theater. Complex services can be designed in a compositional way by first designing the simpler services, and then composing them into a complex service.

The notion of 'contract' has been introduced in software engineering in Meyer's [16-18] design by contract, which is a well-known software design methodology that views software construction as based on contracts between clients (callers) and suppliers (routines), relying on mutual obligations and benefits made explicit by assertions. It has been developed in the context of object-oriented programming; it is the basis of the programming language Eiffel; and it is well suited to design component-based and agent systems. The advantage of the methodology is that it clearly defines the interaction between callers and routines in terms of their interfaces. However, there is still a gap between this methodology and formal tools supporting it. For example, dealing with contract violations is realized by exception handlers, whereas it is well known in the area of deontic logic in computer science [19] that violations and exceptions are distinct concepts that should not be confused.

'Service contract' combines the two concepts. Again the interaction between caller and routines is defined in terms of mutual obligations and benefits, but this time the notion of contract has been extended with the concept of service-level agreements. The service level describes the quality level of the service. However, formal coordination techniques have focused on the coordination of the contract protocol, and have paid less attention to the quality of service (QoS). The problem is that the QoS is a value instead of just information, and values have properties less easily captured by computer science formalisms.

'Quality' (of service, QoS) is defined as the control mechanism for resource reservations. QoS guarantees a level of performance, such as bit rate, delays and the packet dropping probability, to a data flow. The perceived QoS is also called the quality of experience (QoE) and is an important measure for the design of ambient intelligent systems as it captures, from the user's point of view, the end-to-end performance at the service level. To make users' experience seamless, users should be able to perform their tasks without interruptions even though resources and device types and locations are constantly changing. Moreover, they should be able to use all accessible resources within run-time ubiquitous computing environments with maximum efficiency, while taking into account possible threats and the demands for quality of protection (QoP) [20-22].
'Coordination' is emerging as an interdisciplinary concept to deal with the complexity of compositionality and interaction. Compositionality is a central concept in computer science for which many models and tools have been developed, including coordination languages, which are also applied to the composition of services. They can successfully model the interaction between services, but they are less successful in decomposing the quality of a composed service into terms of the qualities of the services it consists of, and more generally they are less successful in splitting up a servicelevel agreement of a composed service in to service-level agreements of partial services. There are many definitions of coordination. For example, coordination has been defined in management science as the 'management of dependencies among independent activities' [23], in agent theory as 'the process by which an agent reasons about its local actions and the (anticipated) actions of others to try to ensure the community acts in a coherent manner' [24], in social theory as 'the activity that involves the selection ordering and communication of the results of agent activities as that an agent works effectively in a group setting' [25] or as 'a process in which agents engage in order to ensure a community of individual agents acts in a coherent manner' [26], in computational intelligence as 'a way of adapting to the environment' [27], and in computer science as the study of the dynamic topologies of interactions among Interaction Machines and the construction of protocols that ensure well-behavedness [28].

Coordination languages, models and systems constitute a recent field of study in programming and software systems, with the goal of finding solutions to the problem of managing the interaction among concurrent programs. As such, coordination focuses on patterns that specifically deal with interaction. It has mainly been applied for coordinating data streams, but it can also be used for other coordination tasks.

\subsection{Summary}

Socio-cognitive concepts are used in various areas of computer science in a variety of ways, both in interdisciplinary areas like business informatics or MAS, as well as in more traditional areas of computer science like software engineering. Such social concepts get a more precise and computational interpretation, which may differ from the interpretation in its original discipline. If conviviality is to be added to this list, we need to develop concrete tools or techniques for incorporating, measuring or predicting the emergent conviviality.

\section{RUNNING EXAMPLE: AMBIENT INTELLIGENCE IN DIGITAL CITIES}

In this section we introduce the context of the research on digital cities; then we introduce our running example where ambient intelligence applications are used in digital city; and finally we 
discuss how this running example is a prototypical instance of a much larger class of examples, where the material world meets the virtual and social worlds.

\subsection{Digital cities}

One can argue whether they are for the better or the worse but what is certain is that since their inception, digital cities have continuously been evolving. This, of course, makes it difficult to define what digital cities really are.

In short, digital cities are web portals that use the metaphor of the real physical city to provide virtual information spaces. As a result, there are many different kinds of digital cities depending upon the proportion between the political, economic and social activities provided to users.

Social virtual worlds such as SL and the Habbo Hotel, are a growing form of digital cities. They originally provided a communication medium to their users primarily to conduct social experiences through role playing. It offers users the opportunity to 'experiment with new forms of solving problems and coordinating social life' according to den Besselaar et al. [29]. However, the size and vitality of these 'massive multiplayer communities' has recently attracted advertisers and businesses that are now adapting their professional services to these virtual communities. Therefore, activities on these portals that were predominantly social and to a lesser extent economic and political today tend to have increasing economic activities. Is this a threat for other digital cities?

Commercial portals certainly have to react to this menacing evolution. eCommerce portals, such as MSN CitySearch, and AOL (America On Line) 'Digital Cities' traditionally offer commercial services, shopping, entertainment and more generally, local easy to find and search information. They provide practical resources for the organization of everyday life and support local economic activities. The purpose of these digital cities is predominantly economic and to a lesser extent social and political. However, to compete with the menacing success of social virtual worlds, they now develop social network activities such as Yahoo! 360 degree photo sharing site and Google Terra Nova 3-D virtual worlds. Frontiers are getting blurred.

That also goes for official administrations and countries, the third kind of digital cities: the eAdministrations, eCities and eGovernments, such as eLuxembourg and digital Shanghai. These official portals of cities and countries provide useful tools to both administrations and citizens. The purposes are not only to improve administrative efficiency and accessibility but also local democracy, social cohesion and participation in elections. These digital cities provide local social information infrastructures over the real city with public and administrative services to citizens and visitors. Although initially top-down organizations, they now try to balance their activities with grassroots initiatives such as forums and online live interactions of citizens to town meetings. In USA, for profit businesses and non-profit organizations co-exist and compete; in EU the attempts are to coordinate administrations, companies and citizens; whereas in Asia, government-directed growth is pursued. The activities in these digital cities are still predominantly political and to a lesser extent, economic and social. However, distinctions are getting smaller.

For den Besselaar et al. [29] digital cities 'may become a tool that enables people to do things by mobilizing the available local resources, using existing and emerging social networks'. Moreover, to gain new members and sustain loyalty of their member base, commercial digital cities have to keep innovating: members invest time and efforts to construct their avatars, fill their calendars and elaborate vast social networks and communities of friends. Similarly, to reach citizens and fulfill the mandates of politicians and administrators, public digital cities have to enforce technological and social progress.

A prevalent idea is that public digital cities 'provide infrastructure for networking local communities and to promote social interaction among people who visit or reside in a city' [30]. Furthermore, to meet these goals, many strategies are currently being used and more are being investigated.

In a word, the success factors of digital cities consist in achieving participation of institutions and communities, balancing the top-down direction, needed for technical infrastructure, and the grassroots initiatives, necessary to insure citizens' cohesion and finally in finding equilibrium between economic and civic motivations. The goal is to 'transform, modernize and improve the level and quality of life of the population at both individual and community levels' [31]. Ultimately, digital cities need to deal with the same complexity as real cities to attract and retain usage, and to function as entities that augment their physical counterparts.

One of the challenges linked to these success factors of digital cities is the connection between physical and digital cities. This relation is one of the main topics of research in this field addressed such issues in the proceedings of digital cities [29,32-34], besides focusing on concepts such as eDemocracy and conviviality, referring then to qualities such as trust, identity and privacy.

The vision of ambient intelligence is more directed towards physical than digital cities, since the intelligent and intuitive interfaces embedded in everyday objects' typically refers to physical objects. It is only through the relation between the physical and virtual worlds that ambient intelligence plays a role in digital cities. However, whereas at this moment the virtual and physical worlds have limited interactions, it is expected that they will be much more intertwined in the future. To illustrate this growing trend, we present several use-cases of this interaction in the following section.

\subsection{Ambient technologies for digital cities}

In this section we introduce a number of use-cases to illustrate how ambient intelligence pertains to digital cities. These 
use-cases are used in the remainder of the article to illustrate the role of conviviality in ambient technologies.

\subsubsection{Use-case 1: Judy in Paris}

Judy just arrived in Paris. It is her first time in the city. She is eager to find a quaint outdoor restaurant and settle down for a nice lunch. Her profile, including a list of her favorite foods, is memorized in her mobile phone. Her profile preference is set to a search distance of a five hundred meter radius. The digital assistant brings up a selection of appropriate restaurants within that range, and options to view video trailers of places. Judy selects her social networks to check the restaurants' ratings. She selects one of the restaurants and the digital assistant proposes ways to get there from this location. Additionally, the assistant proposes a restaurant further away but offering special student discounts. Judy is a student, a high-priority trait in her profile. She selects the restaurant and her phone instantly brings up a map and the itinerary she would most enjoy to get there, e.g. the customized option: whenever possible, walking through parks. The assistant then signals the presence of digital notes in this area. It displays an 'at a glance' overview of the location-based information space. Many digital notes are been left by other mobile users. Judy sets her phone to receive all notifications and start reading the notes while on her way to the restaurant.

At this particular location, someone named Arthur left information about this special tree planted two hundred years ago, and further away an anonymous note mentions a historical event. A few steps further, someone nicknamed Laura signals that a sale on sports clothes will occur in two hours in a nearby store. She sends back a note asking if the store has MyBrand's clothes. A few seconds later, she receives an instant message (SMS) from a store employee confirming it. Judy is thrilled: she will be able to redeem the voucher for a MyBrand's shirt she won, a few days ago, at a raffle on the virtual world Third Life. Judy sends an SMS to her friend Kate to meet her virtually at the store in two hours to choose the shirt with her. Judy has now reached the restaurant; definitely a popular place with students. After lunch, she sends a digital note from her current position to comment on the food and leaves for the clothing store.

\subsubsection{Use-case 2: Harry in Chinatown}

Harry is going out to buy a gift for his neighbor's party tonight. 'I want to go to Chinatown, take the widest road' asks Harry to his car's digital assistant. 'Ok, it will take about half an hour' answers the assistant. The assistant uses personalized information to do its automatic driving and parks the car in the hot spot area where Harry will be able to pay his parking fee to the city directly from his mobile phone. Harry knows Chinatown fairly well as, every week, he logs on to New York City $3 \mathrm{D}$ virtual city to play cards in a virtual club located in Chinatown and usually prefers walking through the streets of Little Italy rather than being instantly teleported. He is wearing his privacy jacket to shield himself from the street and other people's wireless devices; it secures his data and preferences.
Harry sets his access to the friends and family option. A few minutes later his mobile notifies him that his friend Nick is close by. Who knows, he may be able to get back the money he lent Nick when he lost at the virtual card game last week! Nick meets him in front of the Chinese gift store. His wife Carol owns a travel agency in SL. Business has taken a new turn since she started giving guided tours of SL islands to executives: a real success. Carol and Nick recently decided to adopt a virtual child, to prepare for the future real family they want to have, and Nick is very excited. He makes his debt payment to Harry from his cell phone, a direct electronic transfer from his bank account to Harry's. Perfect for Harry who, right now, really needed the extra cash!

\subsubsection{Additional use-cases}

Bob arrives late at a professional meeting. Upon his arrival, the mobile devices of all other participants uploaded the pictures that were taken during the meeting: Bob will be able to instantaneously view the meeting pictures. The key issue is to make sure that only the pictures of the meeting are uploaded, nothing else, particularly, no personal pictures. An analogous application for a group of tourists visiting a city is based on tour guides providing explanations about various buildings and events.

Catherine is in Amsterdam playing a virtual tennis game with her friend Ted, who is in Paris. Catherine is an excellent player and Ted often asks that exchanges be replayed in slow motion to learn from her.

Anna, who is American, attends a conference in Spain. Other attendees come from different countries and speak other languages. All attendees are connected via mobile networks and languages are simultaneously translated into English for her. With the mobile network supporting automatic interpretation technology, locations and languages are no longer barriers to education.

\subsection{Virtual, physical and social realities}

Boella et al. [35] distinguish virtual, physical and social reality for ambient technologies. For a user, a successful experience is a seamless experience between the physical world he is actually in and the virtual world the ambient intelligence technology provides him with. This raises the question of the relation between physical experiences and virtual experiences. A further question is how these experiences relate to the social experiences users have while interacting with other users. What are the differences and similarities between social experiences in the physical world and social experiences in the virtual world? Is conviviality different or the same?

\subsubsection{Distinction virtual and physical realities}

Virtual reality is defined as an experience in which a human is 'surrounded by a three-dimensional computer generated representation, and is able to move around in the virtual world 
and see it from different angles, to reach into it, grab it, and reshape it' [36]. The human is immersed in the virtual world, depending on the technology used, and interacts with it through graphic representations. The digital virtual world can be a twoor three-dimensional synthetic representation of a natural or imagined world that includes objects and representations of humans, avatars or agents. A typical example of a virtual world is SL. In our running example 2, Nick's wife Carol has a travel agency in SL. After logging on to her account, she enters the virtual world and becomes her avatar; for the other SL 'residents' (the name of members in SL) she is her avatar. Carol is both virtual reality and physical reality.

Ambient intelligence is the opposite of virtual reality. As the extension of ubiquitous computing, ambient intelligence integrates microprocessors into everyday objects. Riva et al. [37, p. 19] observe that 'virtual reality puts people inside a computer generated world; "AmI" puts the computer inside the world to help us.' Ambient intelligence belongs to physical reality: it creates contexts for humans to interact with themselves, others and their environments. In use-case 2, Harry uses his virtual assistant to drive his car. A more detailed view could show on the dashboard the three-dimensional character interacting with Harry using voice and capturing his voice and facial expression to regulate the driving. Just below the assistant, a conventional user interface brings up additional information in a touch-sensitive panel. Today, one approach is to mix synthetic images and realworld data to transmit context information, therefore blurring the differences between virtual reality and physical reality.

\subsubsection{Distinction physical reality and social reality}

For Searle [38, p. 153], the physical reality 'exists independently of our representation of it,' it is external to our system of representation, to the world of nature, physical particles and fields of force. As our common sense idea leads us to believe, physical reality exists outside of us and is available to all. Indeed, how could people communicate with each other if physical reality was not 'publicly accessible reality'? Hence physical reality does not depend on your or my representation; it is expressed with 'brute' facts, to follow Searle's terminology. In use-case 1, Judy arrives in Paris, a city that exists independently of how Judy or anyone else represents it. Paris has many features and facts, such as restaurants and these 'brick and mortar' constructions are brute facts. In contrast, the facts that a waiter serves Judy a meal at certain listed prices and that she will pay with money that has value in the context of their society are institutional facts.

Brute facts relate to physical reality and exist independently of any human institutions; institutional facts relate to social reality and can exist only within human institutions.

\subsection{Summary}

Social reality comes into our running example in two ways. First, the city is a social reality, besides being the physical reality mentioned above. In use-case 2, Harry drives to Chinatown, parks his car and expects to pay a parking fee. Parking the car is a physical fact, however having to pay a fee for leaving his car in a public place that has a parking meter is an institutional fact, regulated by the city parking commission. The parking meter counts as the fact that this space is owned by the city that applies this fee to raise taxes.

Second, ambient intelligence itself gives rise to a social reality. In use-case 2, Harry's parking fee can be paid by cell phone, with 'Call2park' system; this is part of the city's smart environment. The city connects services and applications with ambient intelligence throughout the city to anticipate the nomadic behavior of citizens and facilitate their interactions. Searle [38, p. 4] states that social reality 'is created by us for our purposes and seems as readily intelligible to us as those purposes themselves'. This directly applies to ambient intelligence.

Social reality is modified by electronic devices that augment the possibilities of social interactions and influences the exchange and interpretation of information in the digital city. Ambient technologies depend on collective use and acceptance to become social realities. They have a major impact on the city by their introduction of new social roles. Boella et al. [35] develop an approach based on institutions to model the social structures that are being developed in ambient intelligence systems.

\section{CONVIVIALITY}

Interestingly enough, the EU was not the first to bring conviviality to the forefront. A handful of scientists and philosophers had previously tackled the concept and shed some light on conviviality. Empathy and reciprocity were foregrounded by Polanyi in 1964. Furthermore Putnam in 1988, considered conviviality as a condition for civil society: a society with political equality, civic engagement, solidarity, trust, tolerance and a strong associative life; all principles of a democratic society.

\subsection{Definitions of conviviality}

Generally speaking, a convivial place or group is one in which individuals are welcome and feel at ease [39-41], but definitions in the literature spread from individual freedom realized in personal interdependence [42], to rational and cooperative behavior [43], to normative instrument [44].

The definitions indicate that the meaning of conviviality depends on the context of use; excerpts are presented in Table 1. In sociology, conviviality typically describes a relation between individuals and emphasizes positive values such as equality and community life; For example, in use-case 1, the conviviality of the system is in that anyone can leave a note for the benefit of anyone else in the community who want to access the notes. However, with power shifting between individuals and groups, 
TABLE 1. Definitions of conviviality.

Etymological and domain specific definitions

15 th century 'convivial', from latin, convivere 'to live together with, to eat together with.' French Academy Dictionary [45]

Adj. Convivial: (of an atmosphere, society, relations or event) friendly and lively, (of a person) cheerfully sociable. Oxford English Dictionary [46]

Technology: quality pertaining to a software or hardware easy and pleasant to use and understand even for a beginner. User-friendly, usability. By extension also reliable and efficient. Grand Dictionnaire Terminologique [47]

sociology: Set of positive relations between the people and the groups that form a society, with an emphasis on community life and equality rather than hierarchical functions. Grand Dictionnaire Terminologique [47]

conviviality relations change: minority and majority groups form, outsiders are excluded and others force their way in. This dynamic and temporal process raises questions such as: How is conviviality created? How does it evolve? What makes it fail?

Sadek et al. [43] define conviviality as the essential and global characteristic of services ... it emerges from the intelligence of the system and not from a set of local characteristics ... that vary depending upon the application context and the types of users.' Consequently a list of criteria will by itself not suffice. Additional critical factors to consider are the relations that bind the criteria together and the way these relations are perceived by individuals. For example, in use-case 1, Judy enjoys social navigation while walking: she reads the notes that others have left there and respond to them if she wishes; they connect. This activity makes her feel welcome as she is free to join in or not in the notes. The dialog criteria are also respecting her privacy as she is not being assaulted by advertising and invaders. The conviviality of the system is also in that she perceives the environment as being flexible to her moves and it allows her to respond to it at her will.

\subsection{Individuals versus groups}

In 1958, Polanyi [48] is the first to use conviviality in a scientific and philosophical context. He describes it as synonymous with empathy 'which alone can establish knowledge of other minds.' By allowing individuals to identify with each other, empathy provides a way to acquire personal knowledge by experiencing the feelings, thoughts and attitudes of an individual. In 1974, Polanyi [49] further describes a community as convivial when it aims at sharing knowledge: members trust each other, share commitments and interests and make mutual efforts to build conviviality and preserve it. In use-case 1, the sharing of informative notes exchanged between visitors particularly illustrates this connection of minds that people establish through their annotated thoughts and concerns: nature, shopping or historical events.

In his 1971 critical discourse on education, Deschooling Society [50], Illich defines a convivial learning experience as one based on role swapping, where the teacher role alternates with the learner role, to emphasize the concept of reciprocity as a key component to conviviality. In 1973, Illich's Tools for Conviviality [42] brings a new dimension to the concept defined as 'an intrinsic ethical value.' Indeed, for Illich, conviviality means 'individual freedom realized in personal interdependence,' it is the foundation of a new society, one that gives its members the means, referred to as tools, for achieving their personal goals: "A convivial society would be the result of social arrangements that guarantee for each member the most ample and free access to the tools of the community and limit this freedom only in favor of another member's equal freedom.' When Judy sends an SMS to contact her friend Kate, she feels comfortable as Kate is free to answer or not, there is no pressure. The technology allows for a convivial exchange that gives freedom to both Judy and Kate.

In the 1980s, Putnam and his colleagues further extend the concept of conviviality as an enhancement to social capital. In 1988, they refer to conviviality as a 'condition for civil society' [51], and in 2000, argue that in a civil society 'communities are characterized by political equality, civic engagement, solidarity, trust, tolerance and strong associative life' [52], stressing the strong link between the performance of political institutions and the character of civil life. For this reason, the city that facilitates communication for its citizens and visitors, for examples, with free access to hot spots through the city allowing such exchanges as the payment of parking or social navigation through notes.

Building on Illich's learning webs, skill exchange networks and peer-matching communication concepts, Papert and Harel [53] and the Constructionists emphasize in 1991 'learning-by-making,' and in 2001, Sipitakiat [40] developed digital technologies for conviviality, stressing the notion of equilibrium. Indeed, over time, group formation changes. For example, new members join the group while others leave or some new goals or rules are been added. To keep its cohesion, the group needs certain stability. These notions of stability have been extensively studied in such fields as economics and game theory $[54,55]$.

In a 2004 semiotics symposium on conviviality, Schechter [41] takes another look at the concept: 'in a basic sense, conviviality is a social form of human interaction'. The author binds interaction to physical experience and recognizes the social dimension of conviviality, as a way to reinforce group cohesion through the recognition of common values. 'Thus the sharing of a certain kind of food and/or drink can be seen as a way to create and reinforce a societal group through a positive feeling of togetherness (being included in/or part of the group), on which the community's awareness of its identity is based.' In use-case 1, Judy goes to have lunch in the restaurant that gives a discount for students because it convivial for her to have a 
meal around like-minded people who have similar expectations about food, style, comfort and prices. Schechter transforms the physical experience of conviviality into a learning and knowledge-sharing experience. 'To know is to understand in a certain manner that can be shared by others who form with you a community of understanding.'

It is worth noting that the conviviality values from a sociocognitive context, such as social cohesion, inclusiveness and participation, by putting individuals at the center of change, coincide with the very values praised by the ambient intelligence vision.

\subsection{The darker side of conviviality}

A negative side of conviviality can however emerge, when it becomes an instrument in the hands of power relations: 'Conviviality is achieved for the majority, but only through a process by which non-conviviality is reinforced for the minority' states Ashby [56], who further denounces the instrumentalization of conviviality when one group is favored at the expense of another, 'truth realities about minorities are built from the perspective of the majority via template token instances in which conflict is highlighted and resolution is achieved through minority assimilation to majority norms.' Imagine that in use-case 1, derogatory jokes were left towards particular ethnic groups, the system then may be convivial for the one laughing at the joke, but not for the ones being laughed at.

'Conviviality masks the power relationships and social structures that govern communities' argues Taylor [44]. She explores the contradiction between institution and conviviality, asking 'whether it is possible for convivial institutions to exist, other than by simply creating another set of power relationships and social orders that, during the moment of involvement, appear to allow free rein to individual expression ...Community members may experience a sense of conviviality which is deceptive and which disappears as soon as the members return to the alienation of their fragmented lives.' For example, in usecase 1 , we assume that the city administrators want to give a positive image of the city and remove any note that is not favorable without mentioning that the site is censured. Then, even though the system installed by the city administrators seems convivial and open to all, the fact is that it is only convivial for those who are in line with the city's policies, and not for the ones who have posted complaints. These issues raise important ethical questions that must be addressed in the new world of ambient intelligence, for example, with guidelines and best practices, that include the point of views of all parties and new coordination theories [57] and mechanisms that manage dependencies among activities.

'Until now, there has been no reasonably comprehensive survey of Ambient Intelligence research projects in Europe, USA and Canada focused on privacy, security, identity and trust issues' states Wright [58] in his Safeguards in a World of Ambient Intelligent project report. No one has considered the range of safeguards needed to protect individuals; for example, in use-case 1, if Judy's personal data is taken while she is accessing the notes, or if the virtual image of Kate is usurped for the meeting with Judy. The negative sides of conviviality, by revealing these mechanisms, indicate what is to be avoided and point to the mix of different safeguards that have to be put in place to adequately protect individuals, groups and institutions.

\subsection{From groups to institutions}

While Lomosits [59] recommends that conviviality be achieved through consensus and not imposed, Hofkirchner [60] identifies the normative idea of unity-diversity as deserving attention 'when applying conviviality to the level of world society.' The author examines the unity-diversity relation, equates the terms unity-diversity with identity-difference and then describes the four resulting scenarios:

(i) 'establish identity by eliminating difference at the cost of the differentiated side,' yielding reductionism and universalism or

(ii) 'of the undifferentiated side yielding unity without diversity, that is particularism, totalitarianism and homogenization;

(iii) 'establish difference by eliminating identity yielding diversity without unity,' that is fragmentation and

(iv) 'establish identity in line with difference yielding unity and diversity.' The achievement of conviviality is in this integration of difference and differentiation of identity, yielding, for example, multiculturalism.

In use-case 1, censuring particular groups or comments would not be convivial as it would suppress dissident views vital to any community and city, but allowing notes from advertisers and malicious users would certainly be non-convivial for citizens and visitors. Conviviality strikes the balance.

'Conviviality (just like conflicts) is based on agreements or contradictions' states Somov [61]. He further explains the normative aspect of conviviality with the idea that conviviality belongs to the area of regulation of human interrelations. This aspect is why conviviality is particularly relevant to future large scale developments of ambient intelligence.

\subsection{Summary conviviality}

A less common view of conviviality, that pertains to sociology, is when it becomes an instrument to exercise power and enforce one point of view over another [44]. Conviviality is then experienced as a negative force by the losing side. Figure 3 summarizes positive and negative aspects of conviviality from different sources. The emphasis is on sharing of common grounds and inclusiveness for the positive side, and on division and coercive behaviors for the negative side. 


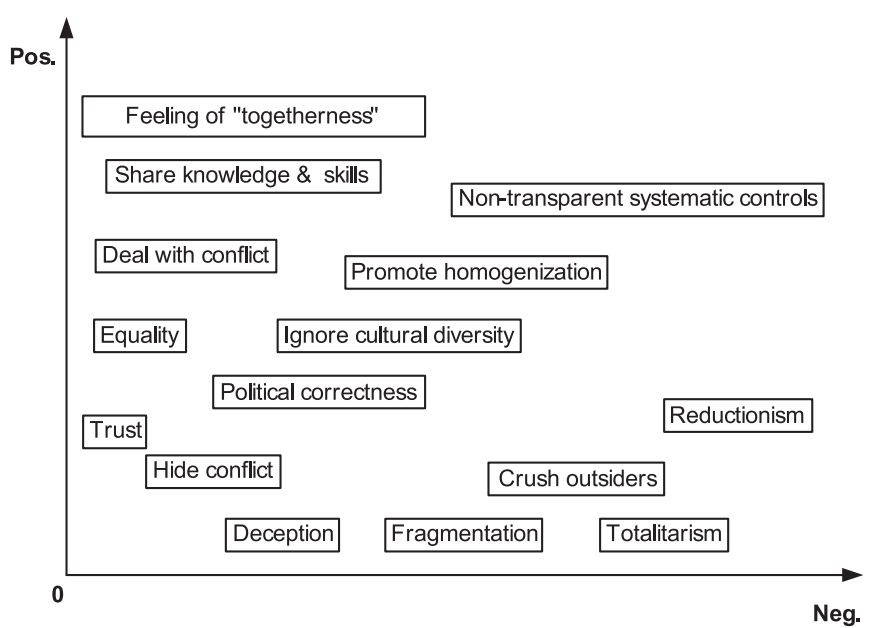

FIGURE 3. Different uses of conviviality.

\section{CONVIVIALITY REQUIREMENTS}

In this section we discuss conviviality requirements for ambient technology.

\subsection{Why do we need conviviality?}

Few will disagree that conviviality is desirable; It has positive effects on society, and it is valuable to people. In social games such as SL, Newbies is the name commonly given to newcomers who do not know yet the rules of the game. It is rare that Newbies escape mistreatment or being taken advantage of by malicious users, also called Griefers. Not a convivial relation for newbies. Recognizing this flaw in their social systems, expert players initiated strategies to create more convivial relations with Newbies: they created services to give Newbies special advantages as a kick-start, for example, free points and advisors to teach them the rules. In other words, they created convivial conditions for Newbies to feel at home, integrate the game and in turn contribute to it. This generous and trusting attitude established a convivial climate. Cooperation ruled again.

Similarly, with ambient intelligence; in use-case 1, gullible new users uploading their notes may give out too much private information giving way to spammers; they may inadequately set up their security levels weakening their device barriers and allowing intruders to access their data.

Nevertheless, conviviality does not only encourage cooperative and collaborative behaviors, it also encourages people to rely on each other, get to know their neighbors, feel closer, and know of each others' habits, thereby reducing the need for strong security measures. For example, in use-case 2, Harry plays virtual card games with Nick, and we assume that these games are convivial as Nick trusts Harry to meet him in real life and wire him some money from his mobile instantaneously while standing next to him, and without fear that he intercepts his personal data. In effect, local groups auto-regulate themselves which, at a micro level, facilitates decentralization.

\subsection{Reconciling freedom with exclusion}

As discussed in Section 4, in 1974, Ilich defined conviviality as 'Individual freedom realized in personal interdependence.' The convivial society guaranties freedom for its members to the point of another member's freedom. As a case in point, in use-case 2, Harry puts on his privacy jacket to ensure that his walk through a populated area like Chinatown will indeed be convivial. As a result he still keeps in touch, connected; he is not isolated as he can still be reached by people he trusts while being shielded from others he may not. Harry feels safe. Indeed, the vital question is not whether society is convivial but whether the conditions for conviviality can be ensured, and for this, institutions have a role to play.

Two decades later, the semiotician Taylor, expanded the debate about institutional power and control over social order with her definition of conviviality as an instrument of deception: 'conviviality masks the power relationships and social structure that govern communities.' For example, we assume that in usecase 1 , the notes are part of a local community project dedicated to openness and democratic spirit. We further assume that the project leaders censure the notes, for example, by making the unflattering and critical comments unavailable to mobile reach. The conviviality users experience while using the system, e.g. posting and reading notes, is deceptive: the leaders control and manipulate the community through it. Taylor further asks 'whether it is possible for convivial institutions to exist?' This outlook is echoed by Ashby when she writes: 'conviviality is achieved for the majority but only through a process by which non-conviviality is reinforced for the minority.' How to reconcile freedom with exclusion?

\subsection{Conviviality for ambient intelligence}

The social navigation system used in use-case 1 illustrates some of the possibilities brought by ambient intelligence. It builds on applications such as the mass-scale annotation system GeoNotes. In this system, users 'annotate physical locations with virtual notes, which are then pushed to or accessed by other users when in the vicinity' [62]. Groups of users are hence formed by region. In social navigation, users further take advantage of social networks. With the set-up of convivial relations and spaces, users are encouraged to share knowledge and cooperate with each other, and discouraged to abuse other users.

Now, we further imagine that the system allows users to instantaneously exchange their pictures, as in [63], when users stand in a particular area, for example, in front of a historical monument. Users would benefit from other user's pictures but not everyone wants to share or merge their pictures. In the context of spontaneous interactions, traditional security, with 
authorizations, is difficult to apply and innovative approaches, based on more dynamic notions such as conviviality, have to be investigated. 'The very notion of ubiquitous capture can be frightening: the potential capture activity of anyone anywhere may change social relations between people.' In an overall computing environment, focus must be on people and their social situations [64]. Because conviviality reinforces commonly shared ground between group members, protective barriers are created between groups and cohesion is favored within the groups, between their members off the groups.

\subsubsection{Cooperating objects}

In the domain of cooperating objects, groups of devices spontaneously team up to form brief information systems and perform actions. This is illustrated by the concept of spontaneous hot spots. For example, if in use-case 1, Judy notices the posting of a sport event and decides to attend it. If, during the event, many fans, Judy among then, send requests from their telephones to get an instant replay of the last action on the field, the video replay resource is simultaneously hit by all the requests. The service is satisfying for all. With spontaneous hot spots, 'Swarms of mobile phones are used to increase the download efficiency of context-related resources in a GPRS network using Bluetooth-enabled cooperation' [65]. As a result, users share the network download cost, the network load is reduced and the download time is shortened.

This type of application however, raises resource-sharing issues, for example, available resources should not be overloading the local communication systems and the continuous process of capture should be accompanied by accurate context descriptions giving secure information on quality and origins of the contributions. It is more convivial for the audience to access the video replay resource, however, it should not be at the expense of local citizens outside the stadium, who still need to use their mobile devices without added lag times; this would not be convivial for them.

\subsubsection{Privacy awareness}

With the increasing number of services and growing capacity of embedded and mobile devices such as PDAs and smart phones, users rely more heavily on these devices to keep their personal data. At the same time people become less aware of the privacy risks they are exposed to: for example in usecase 2, Harry's car retains much of personal information concerning Harry that allows it to drive according to his preferences. This information could fall into mischievous hands and sold to advertisers, Harry could become the target of unwanted sales pitches and spam; even worse, the preferences may be altered: from an itinerary with a preference for toll-free roads to roads with tolls, for example. Current solutions to protect the privacy of users offer them little choice and control over the release of their data. An example of privacy-aware information brokerage framework is the mobile ubiquitous privacy protection for electronic transactions (MUPPET). The system introduces operation-focused access control, allows reward-driven information exchange, includes a purpose detection engine and supports 'explicit as well as implicit purpose activations based on context or authorizations' [66].

Such a system provides ways to differentiate between the goals of the agents that contact users, thereby making them aware of the communication and allowing them to decide whether to accept it or not. Because they increase users choices and possibilities, such tools also increase trust and conviviality. Moreover, the capability of tuning privacy policies at the granular level of exchanges increases the likelihood of obtaining a closer match between the resulting policies and the communication exchanges. However, as the system is based on a constant evaluation of users' communications, the questions to clarify are regarding the evaluation methods and the inference engine that elaborates the policies. Moreover, errors from the purpose detection engine about the type of context users are in could be very damaging for them and make the systems rather non-convivial. In use-case 2 for example, when Nick pays Harry back with his mobile, the device should manage incoming interruptions in a convivial way: if a mistake is made on the context, e.g. not recognized as a high security level financial transaction, and phone calls are allowed during critical operations, consequences can be very damaging.

\subsubsection{Privacy and identity theft}

Few will argue that ambient intelligence brings up dark scenarios. 'What lies at the intersection of privacy protection and ubiquitous computing is easy to imagine: the frightening vision of an Orwellian nightmare-come-true, where countless "smart" devices with detailed sensing and far-reaching communication capabilities will observe every single moment of our lives, so unobtrusive and invisible that we won't even notice!' [67]. To address the privacy challenges raised by ambient intelligence, Langheinrich analyzes and proposes a number of guidelines. Two levels of guidelines are discerned: the easiest to implement given the proper protocols are, for example, to enforce locality by limiting the number of communication hops any message can travel; to prevent unwanted surveillance by creating simple proximity behavior for personal devices, and to provide some baseline anonymity by devising communication protocols that use temporary, random identification. For example, in the additional use-case examples of collaborative pictures, the setting of the boundary that limits where merging of pictures is allowed is crucial.

Guidelines more difficult to implement are, for example: to find adequate security settings as parts of the system may have different security requirements, to create simple mechanisms for pseudonymity-based identity management, to fulfill needed trust requirements by implementing digital signatures with corresponding public-key infrastructure, and back-end systems with privacy-aware databases and access technologies. 
To elaborate guidelines for privacy-respecting infrastructures, laws and codes of practices together with social and technological realities should be taken into account. 'If certain legal requirements are simply not enforceable, technological or procedural solutions need to be found, or the law changed' states Langheinrich. We may have accepted that personal data collection everyday erodes our privacy, however, a number of important threats need to be addressed: 'the improved means of subtly exerting influence and control through the large amounts of personal data that might be collected - not covertly, but as part of freely chosen services such as loyalty programs, recommender systems or payment schemes; the increased risk for identity theft and credit fraud through poorly implemented RFID authentication systems.'

Hence, when developing convivial ambient intelligence tools and systems, it is crucial to clearly state the kind and level of privacy needed and to address ethical issues such as identity theft and surveillance.

\subsection{Summary}

We draw two main conclusions from our discussion. First, requirements for ambient intelligence systems expressed by politicians and managers say that systems must be convivial, whereas ambient intelligence system researchers and developers use other concepts. As an analogy, consider in usecase 2 Nick's wife, who owns and now manages a travel agency. She requires her system developers to have a convivial attitude during a meeting, in order, for example, to make it more efficient. Conviviality during the meeting is used as a tool to achieve the goals of the meeting, and when the employees leave the meeting room, they go back to their conflicted relations with each other. The developers, however, may not understand the notion of a 'convivial attitude.' To model the requirement, the developers may interpret the conviviality requirement as being autonomous to make suggestions, being reactive to direct the discussion in the meeting to reach their goals, being proactive to take the initiative and being goal-directed, and most importantly being social by interacting with others to reach their goals.

Second, when writing down requirements for user-friendly ambient intelligence systems, it is crucial to understand the inherent threads of conviviality. Whereas conviviality was put forward by Illich as a positive concept, negative aspects were also discussed. People are often not rational and cooperative to achieve conviviality [43] and unity through diversity [60] may lead to suppression of minorities. Taylor explores the contradiction that conviviality cannot exist outside institutions: i.e. the question "whether it is possible for convivial institutions to exist other than by simply creating another set of power relationships and social orders that, during the moment of involvement, appear to allow free rein to individual expression. Community members may experience a sense of conviviality that is deceptive and that disappears as soon as the members return to the alienation of their fragmented lives.'

\section{CONVIVIALITY ONTOLOGY}

We are taking up the challenge thrown down by socio-cognitive science in order to structure a response in the field of computer science. What is the bridge? In this section we propose an ontology which straddles the two points of view: Ilich's personal interdependence and Taylor's mask for social structure. The biting point where interdependence and the mask mesh together is not as mechanically simple as this image may suggest. We consider in particular dynamic aspects of conviviality, such as the emergence of conviviality from the sharing of properties or behaviors whereby each member's perception is that their personal needs are taken care of [42] or Ashby's observation that enforcing conviviality for the majority reinforces nonconviviality for a minority [56]. After introducing the ontology as a UML class diagram in Section 6.1, we discuss these three elements of our ontology in more detail, and explain them by examples. In Section 6.2 we discuss dependence networks. In Section 6.3 we discuss conviviality masks, and in Section 6.4 we discuss normative MAS.

\subsection{Ontology}

Our ontology is visualized as a UML class diagram in Fig. 4. An ontology is a set of concepts and relations among them, which can be extended to a conceptual modeling language. On the left-hand side is the usual architecture ontology of software engineering, following the IEEE 1471-2000 standard [8] already mentioned in Section 2.1: stakeholders have a viewpoint reflecting their concerns, which leads to a view on the system. The TROPOS methodology distinguishes between the early and late requirements of stakeholders, which can be expressed in a kind of social network called a dependence network. We discuss these software engineering aspects in Section 7 when we discuss the design of convivial ambient systems.

On the right-hand side of our ontology, we visualize the social concepts. The concept of conviviality is not technical, and therefore it is a challenge to make it applicable for ambient technology. We believe that the ambiguity and vagueness of conviviality is not a valid reason to discard it together with its associated social science literature, because this ambiguity and vagueness holds for most other social-cognitive concepts studied in computer systems, such as 'service,' 'contract' or 'privacy,' as discussed in Section 2. Nevertheless, the discussion on the use of social concepts in computer science also highlighted that we have to choose one of the available definitions. And which one work best in computer science?

One option may be to choose a dictionary definition, because it has common appeal. Returning to the definition of 


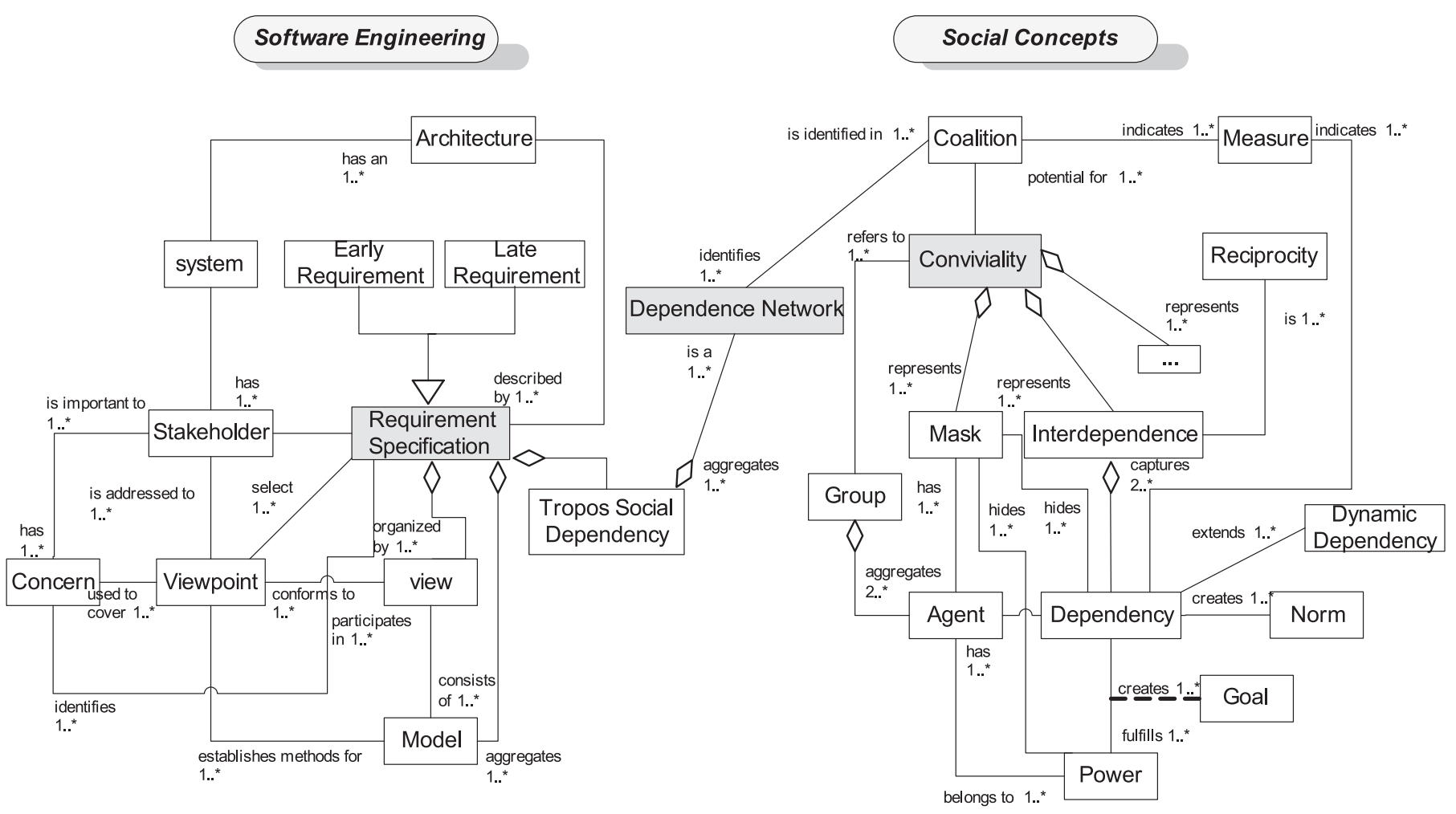

FIGURE 4. Partial conviviality ontology (as a UML class diagram).

Section 4, the Grand Dictionnaire Terminologique [47] defines conviviality as follows.

'Conviviality is the set of positive relations between the people and the groups that form a society, with an emphasis on community life and equality rather than hierarchical functions.'

However, we think the dictionary definition would not be a good starting for our ontology. The definition of the Grand Dictionnaire Terminologique requires that various other vague concepts are made more precise, such as 'positive relations,' 'community life' and 'equality.' Defining one vague concept in terms of other concepts does not bring us much further. However, the existence of various definitions makes it possible to choose one that fits best the interests of the ambient intelligence community, and we therefore use another definition as our starting point. Our criterion to decide for a definition and ontology for conviviality in computer science is that the vague concept of 'conviviality' is related to other concepts used in computer systems, which have got a more technical interpretation. Surprisingly, the most popular promoter of the concept of 'conviviality' has introduced a definition that can be made more precise.

The concept of conviviality was popularized by a book of Illich in 1973 called 'tools for conviviality,' in which he defines conviviality as follows:
Conviviality means 'individual freedom realized in personal interdependence’ [42]

Interdependence and dependencies play a prominent role in many formal systems, such as, for example, Bayesian networks. In this article, the notion of dependence is used as it is in MAS, where dependence relations relate agents who seek to reach their goals, to other agents who have the abilities required to fulfill these goals. Following conventions in game theory as well as MAS, we say that the ability of an agent to fulfill goals of other agents is an indication of its social power.

Thus, our ontology of conviviality in Fig. 4 starts from the definition of Illich, by relating conviviality to dependences between agents. A dependence network is a social network where the relations among the agents are labeled by a goal, expressing that an agent depends on other agents for on the fulfillment of this goal. Thus, dependence networks $[15,68]$ model this interdependence among agents highlighted by Illich [42]. Boella et al. [12] show how dependence networks can be used to determine which reciprocity-based coalitions can be formed, and such reciprocity-based coalitions are an indication of conviviality, because reciprocity plays a central role in conviviality. Conviviality can be measured by the number of reciprocity-based coalitions that can be formed, because if this number is high, then the agents have a lot of freedom in choosing with whom to cooperate to fulfill their goals. As we discuss in Section 7, the number of reciprocity-based coalitions 
that can be formed is also an indication of the conviviality of a design, and can therefore be used as a measure to predict whether the system will be convivial.

Moreover, we need a mechanism to change the (expected) conviviality of a system, we define conviviality masks based on Taylor's idea that conviviality 'masks the power relationships and social structures that govern societies.' [44]

A conviviality mask is a transformation of social dependencies by hiding power relations and social structures to facilitate social interactions.

Here we interpret 'power relations' simply as a dependence between agents, because a dependence reflects that agents have the power to fulfill goals of other agents. For the internal dynamics of such transformations, we introduce dynamic dependence networks, and as a mechanism to enforce conviviality masks, we finally introduce concepts from normative MAS in our conviviality ontology.

\subsection{Dependence networks}

Developed by Sichman and Conte [68] as an extension to dependence network, dependence graphs can express the decentralized structures of dependence relationships in MAS; no agent involved is assigned a privileged role. Dependence graphs can be used for the study of emerging social structures and for managing the complexity of organizations and institutions. These structures are used here to model Illich's notion of personal interdependence. Sichman and Conte [68] write that 'rather than a none-or-all notion [sic], multiagent dependence indicates a phenomenon of growing complexity, from loose group dependence to a more structured and more cohesive collective dependence.'

The following definition makes dependence networks more precise. A dependence network is a social network in which the relations among the agents are labeled by goals. Since sometimes only a set of agents can fulfill a goal without the individual agents having the power to do so, for example, lifting a heavy table of winning the world cup in soccer, the dependence relation is not a simple binary relation among agents, but a binary relation between agents and sets of agents. Moreover, there can be conflicts between goals, such that if a set of agents, agents fulfills some goals, it may be unable to fulfill other goals. We therefore represent the labels by sets o goals that can be fulfilled simultaneously. Finally, we assume that there is a priority order $\geq$ on the goals.

DeFINITION 6.1 (DEPENDENCE NETWORKS). A dependence network is a tuple $\langle A, G, \operatorname{dep}, \geq\rangle$ where:

- A is a set of agents;

- $G$ is a set of goals;

- dep : $2 \times 2^{A} \rightarrow 2^{2^{G}}$ is a function that relates with each pair of an agent and a set of agents all the sets of goals on which the first depends on the second;
- $\geq: A \rightarrow 2^{G} \times 2^{G}$ is for each agent a preorder on sets of goals occurring in his dependencies: $G_{1} \geq(a) G_{2}$ implies that $\exists B, C \subseteq A$ such that $a \in B$ and $G_{1}, G_{2} \in \operatorname{dep}(B, C)$.

Definition 6.2 formalizes that dependence cycles in the graph are potential contracts among the agents, and hence potential indications for conviviality. We therefore analyze cycles and their configurations in the graphs. Indeed, in convivial places each agent potentially contributes to, and receives from, any other agent's goal and the group. However, are all contributions really equally convivial?

DEFINITION 6.2 (RECIPROCITY-BASED COALITION). Given a dependence network $\langle A, G$, dep, $\geq\rangle$, a reciprocity-based coalition is represented by coalition $C \subseteq A$ together with dependencies dep' $\subseteq$ dep, such that for each agent $a \in C$ we have $\exists G, B, D$ with $G \in \operatorname{depend}(B, D)$ such that $a \in D$ (agent a contributes something) and $\exists G, B, D$ with $G \in \operatorname{dep}(B, D)$ such that $a \in B$ (agent a receives something from the coalition).

From the different types of dependence relationships, some, rather simple, involve two agents that depend on one another for their different goals. They are referred to as reciprocal dependence; Fig. 5a, illustrates that agent $A$ depends on agent $B$ for goal $g_{1}$ and $B$ depends on $A$ for goal $g_{2}$. More complex relations involve more than two agents, where each may receive help from an agent and may provide help to another. They are referred to as AMONG-dependence; Fig. 5b illustrates this relation between agents $A, B$ and $C$. In sociology, the latter is referred to as a generalized form of exchange, potentially requiring complex negotiations. Even more complex relations involve an agent $A$ that depends on a second agent $B$ for a goal $g_{1}$ if it is created by a third agent $C$, giving rise to coalition formation (Fig. 5c).

EXAMPLE 1. Let DP1 be the dependence network visualized in Fig. 6. For simplicity, we write:

$\operatorname{dep}(J,\{R\})=\left\{\left\{g_{1}\right\}\right\}$ as $\operatorname{dep}\left(J,\{R\},\left\{\left\{g_{1}\right\}\right\}\right)$ to express that $J$ depends on $R$ for goal $g_{1}$. The figure should be read as follows.

- Agents $A=\{J, R, N\}$ : Judy, Restaurant and Digital Notes.

- Goals $G=\left\{g_{1}, g_{2}, g_{3}, g_{4}, g_{5}\right\}$.

- The dependencies are: $\operatorname{dep}\left(J,\{R\},\left\{\left\{g_{1}\right\}\right\}\right), \operatorname{dep}(R,\{J\}$, $\left.\left\{\left\{g_{2}\right\}\right\}\right)$.

- $g_{1} \geq_{(J)} \emptyset: J$ prefers to get a nice meal than to have nothing.

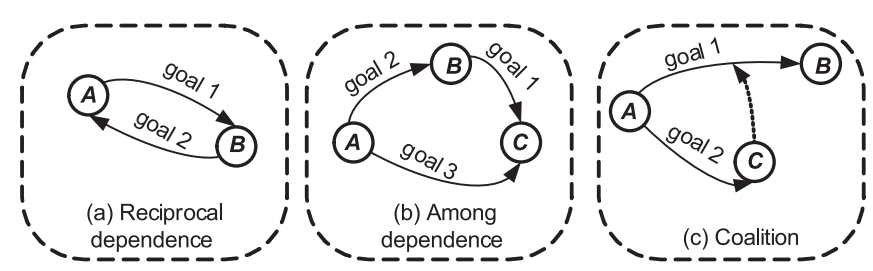

FIGURE 5. Three different types of dependence relations. 


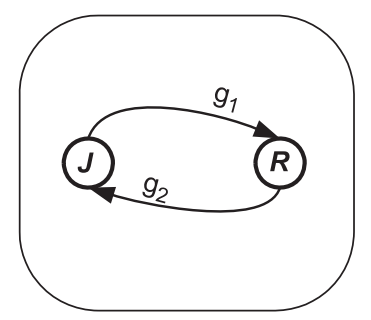

FIGURE 6. DP1: Use-case 1 dependence network for the goals $g_{1}$ and $g_{2}$.

\begin{tabular}{cl}
\hline Goal & Goal meaning \\
\hline$g_{1}$ & Get a nice meal \\
$g_{2}$ & Get customers \\
$g_{3}$ & Get good reviews \\
$g_{4}$ & Leave notes \\
$g_{5}$ & Get city information \\
\hline
\end{tabular}

FIGURE 7. Table of goals.

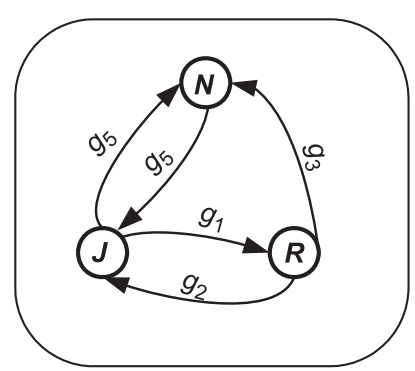

FIGURE 8. DP2: Use-case 1 dependence networks extended from DP1 with additional goals and agents.

Figure 6 illustrates the case for use-case 1 where Judy wants to get a nice meal. There is only minimal interaction between users, however, each user fulfill his/her goal. No ambient intelligence device is used.

EXAMPLE 2. Building on DP1, new goals, listed in Fig. 7, are activated and new agents added. The set $N$ is the set of digital notes left by users. Let DP2 be the dependence network visualized in Fig. 8. The figure should read as DP1 with the following additions:

- The dependencies are: $\operatorname{dep}\left(J,\{N\},\left\{\left\{g_{5}\right\}\right\}\right)$, $\operatorname{dep}\left(N,\{J\},\left\{\left\{g_{4}\right\}\right\}\right)$ and $\operatorname{dep}\left(R,\{N\},\left\{\left\{g_{3}\right\}\right\}\right)$.

- $g_{1} \geq_{(J)} \emptyset: J$ prefers to get a nice meal than to have nothing.

The following definition formalizes that the number of ways to form coalitions is an indication of conviviality.

Definition 6.3 (Conviviality measure). Given a dependence network $\langle A, G$, dep, $\geq\rangle$, conv(DN) is the number of distinct potential coalitions which can be defined in DN.
In DP2, the location-based information space provides digital notes through mobile networks. Judy can consult the notes to find and select a restaurant.

Analyzing the graphs, we note that the number of cycles in DP2 is greater than in DP1. The number of reciprocity relations among the agents is greater indicating greater conviviality in DP2 than DP1.

For the dependence network DP1, the conviviality $\operatorname{conv}(\mathrm{DP} 1)=1$ because there are two cycles in the graph; one potential coalition between agents $J$ and $R$. For the dependence network DP2, the conviviality conv(DP2) $=5$ because there are potentially five cycles in the graph; five potential coalitions between agents $J, R$ and $N$.

A number of other measurements of the cycles in the graph can be taken, each potentially indicating the conviviality of the network, for example, path length. Structural measurements can be obtained by computing for each node, the ratio of incoming edges to outgoing edges. For example, what happens if one removes the node corresponding to the leader of a group in a centralized group dependence graph [69]?

In addition, we need to analyze the different types of dependencies: the dependencies on social norms may have specific mechanisms different from the dependencies on institutions. For example, in use-case 2, the payment of parking fees is, for the state, a way to raise taxes, reduce pollution and regulate traffic while for the car driver it has different meanings.

\subsection{Acting with conviviality masks}

The following definition formalizes that a conviviality mask transforms a dependence network into another dependence network. It can both delete dependencies as well as adding new ones. By transforming the dependence networks, also the conviviality can change, in the sense that the conviviality measure may change.

Definition 6.4 (CONVIVIALITY MASK). Let $\mathrm{DN}$ be the set of all dependence networks. A conviviality mask $\mathrm{cm}: \mathrm{DN} \rightarrow \mathrm{DN}$ is a transformation function between dependence networks.

Conviviality masks are illustrated in Fig. 9. Given a dependence network, the conviviality mask creates a new dependence network. Visually, conviviality masks may be seen as overlays, removing some dependencies while introducing others.

To play a role, you need a mask. How could Judy, in usecase 1 , order the waiter to bring her a meal if not for the mask they both wear given the circumstance: clients are assured that waiters will respond by bringing them a meal, as expected; similarly, clients will act as waiters expect. To get a closer look at the relation between mask and role, we analyze the scenario of a meeting between colleagues and their supervisor. The colleagues have their own personal conflicts with each other, however, during the meeting all get along fine and the work is done efficiently. What happened to their conflicts? 


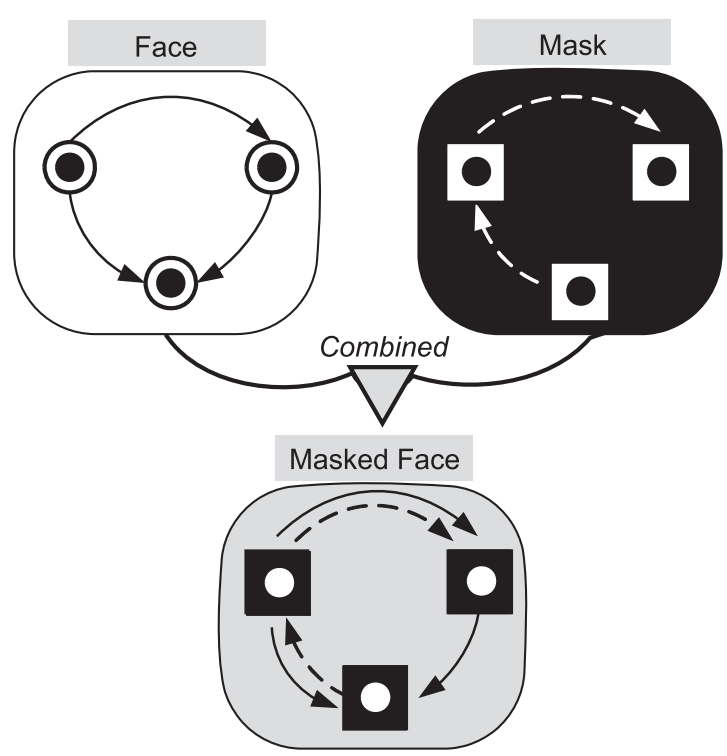

FIGURE 9. Conviviality mask.

Simply put, the colleagues set their expectations differently depending upon if they are in the meeting or not, masking the expectations that are not related to the situation, during the meeting. Hence, the mask is triggered by dependence relations, and uses roles to set patterns of expectations. In other words, the mask is a tool that filters the appropriate sets of relations for specific sets of situations. The mask allows relations to unfold without conflict, which is what groups and organizations strive for in order to reach a stable state and last. In use-case 1 for example, we assume that the system users, instead of wearing a convivial mask and leaving courteous notes, start leaving hate notes and malicious information; users would then not trust the system and rapidly drop it. This ties up with Taylor's definition: 'conviviality masks the power relationships and social structures that govern communities.' The conviviality mask, therefore, raises the questions of the use and misuse of conviviality and how to understand it.

The following definition illustrates how the dependence networks can be modified such that the power of agents to change dependencies among agents is captured in the network itself. To model conviviality masks that introduce new goals and therefore create new dependencies among agents, we introduce dynamic dependence networks [70]. As, due to agents' actions, dependence relations among agents can evolve overtime, we extended dependence networks to dynamic dependence networks: agents have the power to create new dependencies in the network.

DeFinition 6.5 (DyNAMic DEPENDENCE NETWORKS). A dynamic dependence network is a tuple $\langle A, G$, dyndep, $\geq\rangle$ where:

- A is a set of agents;

- $G$ is a set of goals;
- dyndep : $2 \times 2^{A} \times 2^{A} \rightarrow 2^{2^{G}}$ is a function that relates with each triple of sets of agents all the sets of goals on which the first depends on the second, if the third creates the dependency;

- $\geq: A \rightarrow 2^{G} \times 2^{G}$ is for each agent a total pre-order on goals which occur in his dependencies: $G_{1} \geq(a) G_{2}$ implies that $\exists B, C \subseteq A$ such that $a \in B$ and $G_{1}, G_{2} \in$ depend $(B, C)$.

The power to change the goals of an agent, or to make these goals irrelevant, allows an increase or decrease of conviviality in the system. For example, in use-case 1, we assume that Judy's friend, Kate, has the physical voucher in her hands and that it is needed to present the actual voucher to redeem the shirt. When Judy sends an SMS to Kate to ask her to meet her at the store to choose the shirt with her, she now needs to meet her in person, so that she brings the voucher. Judy depends on Kate, but Kate does not depend on Judy and may not come. Not a convivial situation. Now, if on the contrary the voucher can be redeemed electronically, or Kate wins a gift if she brings the voucher, then the dependencies are shifted: the former action removes Judy's dependency on Kate while the latter adds a dependency from Kate to Judy. The conviviality mask is put on when Judy asks Kate to come and help her choose the shirt whereas, in fact, she needs her to be there for the voucher. It is therefore a complete transformation of social dependencies that is performed by the conviviality masks: Hiding and revealing the power relations and social structures, conviviality masks facilitate social interactions.

In a dynamic dependence network, agents have the power to fulfill goals and to create new goal dependencies, e.g. to combine powers to create goals, to create new powers and to change priority relations. The conviviality mask allows adding and removing goals and powers, e.g. abilities, to and from agents in order to adapt the conviviality to specific types of requirements. Banking transactions, for example, in use-case 2 when Nick pays his debt with his mobile phone, require high security and differ from the digital notes exchange requirements from use-case 1 . Of course, conviviality can also decrease dependencies, for instance, by making goals irrelevant, or by assigning new skills to agents so that they are self-sufficient. For example, if the digital notes were very informative, city visitors may not need the tourism office any longer.

\subsection{Normative MAS}

In this section, we relate conviviality masks to normative MAS. Why MAS and why normative? First, in MAS, an agent is defined as 'a computer system that is situated in some environment and that is capable of autonomous actions in order to meet its design objectives' [71]. In short, agents can cooperate and coordinate their actions and negotiate with each other. Most interestingly, this autonomy allows agents to take decisions, to 
anticipate social changes and react to it. In a group of agents designed to be convivial, if an agent $A$ decides to behave aggressively towards others, hence violating conviviality rules, then the rest of the group must take action against $A$. Agent $A$ should be sanctioned.

Boella et al. [72] define, a normative MAS as a system in which agents can decide whether to follow the explicitly represented norms and can modify the norms following the systems' specification. In the above example, the conviviality specification should dictate how and to what extent the agents can modify conviviality relations in this context and what sanctions non-conforming agents should incur. This, of course, raises the question: what are convivial requirements?

Adding new technological devices to a system changes the relationships among agents: it changes the roles agents hold and the roles that constitute the institution. For example, in our use-case 1, we assume that Judy is at the restaurant, a group of students enter with their professor for a lunch meeting. One student, Fred, senses Judy's device and they start communicating with SMS and instant messaging. We assume that the professor can see the students' communications on her own device and block them at will: another role is added to the professor, e.g. blocking communication that is not relevant to the meeting, which gives her additional power. In multiagent perspectives, such social roles are instances that can be added to the agents' roles. Obligations and permissions are fundamental features of normative systems; they usually include the notion of power and specify their normative and institutional qualities. The institutional level of a role describes the agent's public beliefs and goals; it is highly relevant as it is where different types of powers are associated. Social institutions are entities that exist not only through the collective consent of public beliefs and goals but also through their regulating rules. Consequently, a role cannot impact an institution without public consent, that is, the agents' social system. Indeed, social and institutional systems, as previously seen in Section 3.3, are not physical realities and do not exist without public consent. For example, institutional views can be defined as follows:

DeFinition 6.6 (InstiTUtional VIEW [35]). IV $=\langle$ RL, IF, $\mathrm{RB}, \mathrm{RG}$, IX, beliefs: RL $\rightarrow 2^{\mathrm{RB}}$, goals: RL $\rightarrow 2^{\mathrm{RG}}$, skills: $\mathrm{RL} \rightarrow 2^{\mathrm{X} \cup \mathrm{IX}}, \mathrm{IR}: 2^{\mathrm{X} \cup \mathrm{IX}} \times 2^{\mathrm{RB}} \rightarrow 2^{\mathrm{IF}}$, roles: $\left.\mathrm{RL} \rightarrow A\right\rangle$ consists of a set of role instances $\mathrm{RL}$, a set of institutional facts $\mathrm{IF}$, a set of public beliefs attributed to roles $\mathrm{RB} \subset \mathrm{F} \cup \mathrm{IF}$, a set of public goals attributed to roles $\mathrm{RG} \subset \mathrm{F} \cup \mathrm{IF}$, a set of institutional actions IX, a function beliefs that relates with each role the set of its public beliefs, a function goals that relates with each role to the set of public goals it is committed to, a function skills that describes the institutional actions each role can perform, and a set of institutional rules $I R$ that relates sets of institutional actions, sets of facts and institutional facts with the sets of institutional facts they see to. A function roles assigns a role to its player in $A$.
Clearly, private and public levels have to be separated to avoid possible conflicts between the agents, beliefs and the actions they have to perform in order to realize their goals [73]. However, for an agent to be coherent, its private beliefs and goals and its public beliefs and goals, although not necessarily the same, must be connected. For example, an agent may have a number of private beliefs and goals as $b_{1}, b_{2}, b_{3}, g_{1}, g_{2}$ and public beliefs and goals as $b_{1}, b_{4}, g_{2}, g_{3}, g_{4}$. In the example above, Fred may have a private belief that the professor is not competent, but his public belief is that the professor is competent, as in an educational institution, professors are supposed to be competent and students are supposed to recognize it to learn from them. Therefore, a function must relate a private level to an institutional level for beliefs and for goals. What then is the difference between the two levels? Power. Indeed, at the public level, an agent can have the power to add to, remove from and edit the goals and beliefs of other agents' public sets; this is not the case at the private level. In our example above, the professor is not only able to stop Fred' $\mathrm{s}$ messages to Judy, but also to prevent future messages, for example, by promising a sanction, thereby removing Fred's goal to communicate with Judy.

\subsection{Summary}

An ontology is a set of concepts and relations among them, which can be extended to a conceptual modeling language. Our ontology starts from Illich definition of 'individual freedom realized in personal interdependence,' and formalized conviviality in dependence networks. We measure the conviviality by counting the number of potential coalitions in a dependence network, since a larger choice in coalitions represents more freedom for the agents regarding who to work with. We define conviviality masks as transformations of social dependencies by hiding power relations and social structures to facilitate social interactions. As a mechanism to enforce conviviality masks, we finally introduce concepts from normative MAS in our conviviality ontology.

\section{CONVIVIAL DESIGN}

The conviviality ontology visualized as a UML class diagram in Fig. 4 illustrates that the bridge between the social ontology and the design of ambient technology is via the dependence networks. When early requirements are represented as dependence networks, as in the TROPOS methodology, we can very early in the design of the system get a first indication of the conviviality of the system, by applying our conviviality measure. In other words, if the dependence network written down contains many ways for people to interact, then it is more likely that the system will be convivial, and if there is only one fixed way in which people can interact, it is likely that the system will be less convivial. Of course, like 
any measure that can be applied in early design, it is only a very rough measure. However, in our experience, it helps to discuss with the stakeholders during the requirement process to focus attention away from traditional usability concerns, toward cooperation among the agents. In this section, we first give some additional background to this use of dependence networks in early requirements; thereafter we discuss other uses of conviviality.

\subsection{Conviviality measures in TROPOS}

In a software engineering life cycle, requirements express the customers' wishes about what the system-to-be should do. In the early requirement phase, information is gathered and analyzed, while the late requirement phase produces specification documents intended for developers. Most of existing requirements techniques have been designed for late requirement phases and focus on completeness, consistency and verification, while early requirements have often remained incomplete, inconsistent and ambiguous. The early phase, however, has received increasing attention for being crucial to the success of system development and deployment. Particularly important questions addressed during early requirement phases of a life cycle include: How to address stakeholders' interests and concerns? why is the system needed? what are the alternatives? and what are the mutual concessions stakeholders must agree to in order to resolve conflicting situations? $i^{*}$ proposes to address these questions, in-depth and at the initial phase of the requirement process, with the notion of intentional actor that represent stakeholders' intentions and mental states.

The agent-oriented modeling language $i^{*}$, which stands for distributed intentionality, was developed for modeling and reasoning about actors' intentions, their organizational environments and their information systems [74]. $i^{*}$ is particularly appropriate to look inside the actors' minds therefore allowing to analyze when, and possibly why, an actor assesses a group or interaction as convivial or not convivial. Moreover, $i^{*}$ represents relationships among actors as sets of dependencies. In this sense, $i^{*}$ is similar to social network methodologies that use relational concepts and analysis of actors interdependencies, relational ties patterns and structures. These structures can be further analyzed using dependence networks. The $i^{*}$ framework stands on the representation of two different abstraction levels, the intentional level and the rational level. The intentional level, represented by the Strategic Dependence (SD) model, offers a deep understanding of the stakeholders' needs in relation with the organization it belongs to. SD models describe the dependence relationships among actors in the organizational context. The rational level, represented by the Strategic Rational (SR) model, provides an explicit representation and reasoning about the stakeholders' interests and how different configurations of the system address them or impact them. SR models, building on the SD models, provide a more detailed level of modeling, by procuring insights on the stakeholders' mental states, allowing the evaluation of alternative means to reach a goal and help identify other alternatives, from the stakeholders' point of view.

In $i^{*}$, the $\mathrm{SD}$ model is represented by a graph, depicting a high-level analysis of stakeholders' social dependencies identified by analyzing users' interview reports and domain information. Actors, representing stakeholders and depicted by nodes, are endowed with intentional properties, e.g. goals, beliefs and abilities. The edges of the graph represent the dependence relations among the actors. Actors depend on each other for a number of reasons: to reach goals they can not reach by themselves, to obtain a resource needed to fulfill a particular goal and to perform tasks for which they lack the capabilities. Dependencies represent actors' reliance on each other while they seek to achieve their goals. Hardgoals are distinguished from softgoals: the former are concrete goals expressed as functional requirements, while the latter, difficult to quantify, are evaluated qualitatively and expressed as non-functional requirements for the system; they have 'no clear-cut definition and/or criteria for deciding whether they are satisfied or not' [75].

\subsection{How to use conviviality measures?}

During design, the question we ask for each process is: how convivial is this situation? Hence, we look through the conviviality prism from different angles; we show how that conviviality is vital for software system design; and finally, we pin down the means to achieve it. The conviviality measure starts from the number of dependencies present in the dependence network that represent the system. This measure is low if there are only few dependencies among agents: a few coalitions become possible. However, the number of dependencies is not the only relevant measure, but also their distribution must be considered. Besides counting only the number of potential coalitions, we can define also the following measures [70]:

- Whether a dependence can allow an agent to enter a coalition, since he has some power which allows him to reciprocate.

- Whether the powers and dependencies are distributed on different sets of agents or not. In the first case, the risk of a non-convivial environment increases.

Additionally, powers, e.g. abilities, can be added to agents in order to create new dependencies for them. These changes can turn a non-convivial dependence network into a convivial one, such as in the following examples:

- If, for a given goal, an agent is dependent on a set of agents, he could be made dependent on different sets of agents. In this case, his negotiation power for entering a coalition increases [69].

- If an agent is dependent on a set of agents, he can be given new powers, e.g. abilities, and therefore rendered more independent. 
- If an agent is dependent on a set of agents, powers, e.g. abilities, can be added to him to make the agents in the set depend on him.

- Powers, e.g. abilities, can be removed from agents who are too independent in order to make them more dependent on other agents.

- Similarly, goals can be added to independent agents to make them dependent on other agents.

In our analysis of these measurements, we have to consider real and institutional powers at the same time, because both contribute to conviviality [76].

Let us consider the design for the use-case 1 running example, where a tourist, Judy, comes to visit a new city. A four-stage design approach is commonly used for the design of digital cities, depending on their level of development, and can be summarized as follows:

(i) Stage 1: forms, brochures and information are put online. There is no interaction capability. Help is provided with a static screen. Judy can check the city web site for information.

(ii) Stage 2: forms can be downloaded but and they have to be sent by mail to the digital city. This is one-way interaction. Help is provided with automatic word completion, tool tips and contextual help. Judy can send a request to the tourism office to get a list of restaurants that give student discounts.

(iii) Stage 3: forms can be downloaded, filled in on line and uploaded to the digital city. This is two-way interaction. Some adaptive access technologies and ad hoc networking and architectures start to establish seamless interoperability among wireless technologies. Help is provided with intelligent agents and expert systems through interactive interface. While in the city, Judy has two-way interaction with other users through the digital notes system.

(iv) Stage 4: interaction between all stakeholders is performed synchronously and asynchronously in both directions. This is full interaction. Pervasive computing and context awareness deliver enhanced, highly usable services to mobile users. Help is provided with an embodied conversational agent, and an adaptive and interactive environment. This process is a difficult process due to legacy systems and migration challenges inherent to large systems such as the ones from a city, and challenges are to ensure that conviviality is part of the design process. Judy may be able to interact with personal digital assistants the city would provide over its ad hoc network to visitors.

Evaluations should be performed for each stakeholder group. Using use-cases 1 and 2 running, a number of metrics are being reviewed for appropriateness:

- Network analysis to evaluate and compare empirical data, for example, from a log collected from experiments with a digital city prototype, over a few weeks or months, to see if the conviviality model actually facilitates conviviality. Is Judy satisfied with the city visit?

- Predictive metrics, or design metrics to assess the quality of designs or prototypes, for example, ease of use for new tourists, like Judy, to find what needed information, efficiency and error recovery.

- Preference metrics to quantify the subjective evaluations and preferences of the stakeholders using the system, for example, the affect of visitors interacting with an intelligent agent, for example, if Harry has a problem with the parking meter and need to connect with an agent, the efficiency of the civil servants, the helpfulness of the social support forum for visitors, the control and ease of learning.

- User interface design metrics: semantic metrics based on content, e.g. how the stakeholders using the system understand the components and their interrelationships; procedural metrics that are task sensitive, e.g. how they follow a use-case by performing various tasks and structural metrics based on surface properties such as, for example, on mobile phones, the number of visual components on the screen and the alignment of widgets.

\subsection{Other uses of conviviality}

We can extend the ontology to a conceptual modeling language, which can be used to define models, views and viewpoints on a system. An approach on social viewpoints is another way to look through the conviviality prism. A person's walk through the process with her/his own view encounters particular situations that can be more or less convivial. In use-case 2 , for instance, Harry commands his virtual assistant by voice as to what kind of street he would like to go through, and the virtual assistant answers by voice and brings up additional information when available and in accordance with Harry's memorized preferences. Harry can always decide to himself drive the car and change the itinerary. The system therefore creates flexible situations for Harry: he gets more options and greater autonomy to achieve his goals. This corresponds to Crosier's 'room for maneuvering' and his concept of zone of influence; ambient technology gives Harry more control on his environment. Ambient intelligence brings conviviality.

Another reason why 'conviviality' is a useful concept for computer scientists, is that the aim of social scientists is not to define the concept, but to create conviviality by creating the desired conditions for social interaction. This coincides with the aim of designers of ambient intelligence, digital cities or virtual communities. For example, Illich defines a convivial learning experience in which the teacher and the student switch roles, such that the teacher becomes the student and the student becomes the teacher. This role swapping emphasizes reciprocity as a key component for conviviality [77]. Such role swapping use-cases can directly be used in ambient technologies. For example, in use-case 1, users alternate 
between leaving and getting notes. The ambient intelligence technology here creates the very possibility of role swapping. In use-case 1, Judy exchanges notes with other system users; all users together engage in back and forth communications, whereby each contributes and receives from the interactions. If most notes were written in a language or protocol Judy would not understand, she would feel excluded, even though for the majority of users understanding it, the system would be convivial. Such a system should therefore be designed to prevent this to happen, for example, by having automatic translations and help to newcomers.

Finally, if people feel more convivial in environments they understand with ease, then we must define simplified normative systems and methodologies to develop abstractions that achieve this. For example, how to develop simplified and transparent systems for new users while preserving all options for expert users? How can we define simplified organizations such that new agents meet only a subset of all agents in the system? How to define simplified regulations, such that new agents can act with more ease? What are the abstractions and refinements to make on the dependence networks to achieve these goals? The digital divide, the gap between technically savvy users and the users, is a concern for politicians and administrators. The EU Simplicity project (www.ist-simplicity.org, 2004-2005) foresaw that systems beyond $3 \mathrm{G}$ and pervasive computing would lead to an increasing number not only of services, but also of many different devices and heterogeneous network access technologies. However today, users who try to use existing services already have to deal with a great numbers and variety of procedures to configure devices, of authentication mechanisms, passwords requirements, payment procedures, access technologies and protocols. Moreover, the increasing number of physical devices users should rely upon and carry around has become a challenge even for technical users. The digital divide is therefore deepened rather than bridged by new technologies and it has become difficult for users to benefit from new developments. The simplicity project was to remedy this situation by simplifying access to services. Throughout the use-cases provided as illustration [78], the emphasis is on the convenience and the apparent facility brought to users. However, as the system relies on the profile, preferences and policy rules defined by the user as well as those self-learned and automatic, the threat lies in the user's diligence to correctly update his/her profile, preferences and rules; a process that can prove to be quite non-convivial. Moreover, the risk of data leakage and a mischievous attack increases with each step. Indeed in use-case 2 , Harry's virtual assistant has first to be set up and configured with his preferences, a crucial step in the design process of the system and one that imperatively requires convivial attention.

\subsection{Summary}

Conviviality is a useful high-level modeling concept for organizations and communities, emphasizing social sides rather than legal sides. Erickson and Kellogg [79] say: 'In socially translucent systems, we believe it will be easier for users to carry on coherent discussions; to observe and imitate others' actions; to engage in peer pressure; to create, notice and conform to social conventions. We see social translucence as a fundamental requirement for supporting all types of communication and collaboration.'

A digital city should be a meeting place for human and artificial agents. In other words, the metaphor of the real city should be underlying the design of the digital city. In particular, using conviviality measures for dependence networks in TROPOS ensures that conviviality, sometimes reduced to user-friendliness, is incorporated to ambient systems' specifications and design. User-friendliness emphasizes unary relations (human/machine) and the notion of 'use', e.g. the taskoriented aspect of Human Computer Interaction concepts such as affordance, ergonomics standards and usability. Conviviality is primarily concerned with relations between users and areas such as adaptive systems, augmented cognition and ambient intelligence. There is a widespread belief that user conviviality is something that can be added to a computer system once it has been developed. However, it is much more difficult to turn a non-convivial system into a convivial one, than developing a convivial system from scratch. Thus conviviality should be incorporated from the first model of the system.

\section{RELATED RESEARCH}

In this section we discuss related research. We start with the research in computer science that has first referred to conviviality. Then we look at the role of norms as it pertains to conviviality and ambient intelligence. Finally, we look at different kinds of user interactions that relate to the concept of conviviality such as artificial companions and mixed initiative interaction.

\subsection{Computer Science approaches}

After looking at the multiple and broad range definitions and uses of conviviality in social sciences, and noting the number and depth of ethical issues discussed in social science regarding the concept of conviviality, we recognize that conviviality raises a challenge for computer science. Which issues are relevant when developing convivial ambient intelligence? How can the positive aspects of conviviality be used for ambient intelligence? How should the negative aspects of conviviality be taken into account?

\subsubsection{The role of conviviality in MAS}

In MAS an agent is defined as 'a computer system that is situated in some environment, and that is capable of autonomous action in this environment in order to meet its design objectives ...Agents are capable of flexible (reactive, proactive, social) 
behavior' [71]. This capability is particularly crucial for ambient intelligence since it allows agents to cooperate, coordinate their actions and negotiate with each other.

\subsubsection{The use of conviviality for intelligent tutoring systems} The system proposed by Gomes et al. [77] provides a recommendation service of student tutors for computational learning environments. 'Each agent pupil represents a pupil logged onto the system. One of the functions of the system is to be the client for an instant message service. Through its agent pupil, any pupil can communicate with other pupils in the system. Another function of the agent pupil is to pass information on the affective states of the pupil. This information can be inferred by the agent or be adjusted by the pupil itself.'

The authors' claim that 'convivial social relationships are based on mutual acceptance through interaction' hence on reciprocity and in this case students helping each other. A utility function takes as input a student's social profile and computes the student's affective states indicating if the student needs help; if s/he does, then the system recommends a tutor. Remaining challenges are with defining utility function inputs to compute recommendations, presently a set of random values, and to automate inferences of students requiring help. This exposes the urgent need for further research in evaluation methods and measures for concepts such as mood, sociability and conviviality.

The technical challenges of developing convivial tutoring systems are pale in comparison with the ethical issues raised by the possible development of such a system: preserving pupils' privacy, securing the information gathered to create their social profiles, deterring possible misuse of pupils' affective states and system errors concerning the data. In fact, it is imperative that designers of such systems use guidelines, for instance, the European Privacy Design Guidelines for the Disappearing Computer [80] in order to 'implement privacy within the core of ubiquitous computing systems' [3]. Noting that these guidelines are not legislative documents, we stress the importance of privacy policies to prevent user mistrust that would jeopardize or seriously hinder the development of ambient intelligence.

\subsubsection{The use of conviviality for conversational agent}

'All service offerings must integrate conviviality to the interaction between user and system as an essential preoccupation' [43]. To fulfill this goal, Sadek et al. define a convivial agent as rational and cooperative. An interaction is convivial 'if the agent presents, jointly and at all times, one or all of the following characteristics: capacity for negotiation, contextual interpretation, flexibility of the entry language, flexibility of interaction, production of co-operative reactions and finally of adequate response forms.' These communicative capacities and social intelligence based on emotional intelligence are crucial to enhance agents' ability to interact with users.

Indeed, building on this work, Ochs et al. [81] distinguish felt emotions from expressed emotions noting that 'a person may decide to express an emotion different from the one she actually felt because she has to follow some socio-cultural norms.' We believe this direction to be very relevant to the evaluation of conviviality as it dissociates personal feeling from social expression.

\subsubsection{The use of conviviality for reputation systems}

Reputation is defined as 'the overall quality or character as seen or judged by people in general and the recognition by other people of some characteristic or ability' [82]. When Casare and Sichman [83] state that 'reputation is an indispensable condition for the social conviviality in human societies,' they emphasize that reputation provides the transparency quality of the information provided with reputation, throughout the group about its member, this transparency insures the conviviality of the group, as all group members receive the same information about their peers. The authors' system insures that everyone is aware of anyone's behavior, that is anyone's compliance or not to the rules of the group. Casare and Sichman define a functional ontology of reputation for MAS whereby 'roles are played by entities involved in reputative processes such as reputation evaluation and reputation propagation.'

The authors' claim is that 'concepts of the legal world can be used to model the social world, through the extension of the concept of legal rule to social norm and the internalization of social mechanisms in the agent's mind, so far externalized in legal institutions.' In their system, the agents' actual behaviors are compared with the social norms observed in their world. The process, however, presupposes an initial reputation profile of users that agents can then update in real time. Reputation acts as a communication tool, ensuring complete social transparency throughout the system. The strict application of norms to reputation however may be difficult and suffer from rigidity. Of course, the same holds for conviviality.

\subsection{The role of norms in MAS and how it applies to conviviality and ambient intelligence}

The role of norms is increasingly getting attention specifically in MAS where the most common view is that "norms are constraints on behavior via social laws' [72]. In their introduction to normative MAS, Boella et al. [72] give the following definition: 'a normative multi-agent system is a multiagent system together with normative systems in which agents on the one hand can decide whether to follow the explicitly represented norms, and on the other the normative systems specify how and in which extent the agents can modify the norms.' Agents therefore decide how to interact with each other, following conviviality conventions or not, they can, also, modify these conventions and thereby contribute to their evolution. Furthermore, the role of norms for conviviality is an instrument for the internal regulation of social systems [84]: for example, in digital cities 'government regulations extend laws with specific guidance to corporate and public actions' [85]. 
Several kinds of norms are usually distinguished in normative systems. Within the structure of normative MAS Boella and van der Torre [86] distinguish 'between regulative norms that describe obligations, prohibitions and permissions, and constitutive norms that regulate the creation of institutional facts as well as the modification of the normative system itself.' A third kind of norms, procedural norms, can also be distinguished as 'procedural norms have long been considered a major component of political systems, particularly democratic systems,' states Lawrence [87], who further define procedural norms as 'rules governing the way in which political decisions are made; they are not concerned with the content of any decision except one which alters decision-making procedures.'

Boella et al. further describe action models where 'agents are goal directed and try to maximize their choice of means to obtain a goal.' It is assumed that an agent belongs to a group and must follow the norms of the group like all other members. In such a system, a strategic reason for an agent to chose one means versus another could be based on the gain of conviviality for the group and therefore, for himself as well.

The role of norms for conviviality reinforces social cohesion by reflecting the group's core values internally as well as externally. By making the rules explicit the role of norms for conviviality contribute to the elaboration of guidelines for conduct such as privacy protection guidelines, crucial for the development of ambient intelligence applications and coordination systems. Finally, the social warranty and protection mechanisms of conviviality are achieved through the expression of its group members' feelings toward each other: praise and encouragements for members who conform to the rules, and anger and blame for the ones who do not. Such behavior coordination and regulation mechanisms are the very ones that underlie future ambient intelligent society and can therefore greatly gain by explicit conviviality specifications, which does not mean that the end-user communication should as well be explicit.

\subsubsection{From explicit to implicit input and output}

In interactive systems, traditionally, a human user communicates and interacts explicitly with the system by using a variety of modalities; however, ambient intelligence creates the need for new forms of human computer interaction, transparent and decentralized. The concept of Implicit Human Computer Interaction (iHCI) proposes to take the users' context into account when creating new user interface for ambient intelligence. Schmidt defines implicit human computer interaction as 'the interaction of a human with the environment and with artifacts which is aimed to accomplish a goal. Within this process the system acquires implicit input and may present implicit output to the user' [37].

The basic idea of implicit input is that the system can perceive the interaction of the user with the physical environment and the overall situations in which the actions take place. The system anticipates the user's goal to provide appropriate support as illustrated by the following use-case: 'the heating/air condition control system of an office building has access diaries of the people working in the building. Office rooms are not heated/cooled when people work offsite or are away. Meeting rooms are heated/cooled in advance of scheduled meetings.'

For more subtle situations, for example, a light that switches on and off depending on the user's action, e.g. reading the newspaper or watching $\mathrm{TV}$, the question is how long a situation has to last before the system takes it into consideration. Issues being raised by iHCI are, for example, How to find and analyze the situations relevant for the system? How to abstract from situation to context? how to link context to behavior? The central questions reside in how to keep users in charge of their interaction and how to achieve a balance between stability and dynamics. Conviviality can address these questions with, for example, the notion of dynamic personal interdependence.

\subsection{Human computer interaction approaches}

According to Lamizet [88], conviviality was elaborated to describe both 'institutional structures that facilitate social relations and technological processes that are easy to control and pleasurable to use.' On the one hand conviviality allows individual expression facilitated by personalized interface and customized content while on the other hand it contributes to the standardization of the media and of representation systems. In her study of animated toys, Ackermann [39], looking at the relational qualities of playthings notes that beyond humanoid traits, it is an AniMate's manners of interaction that matter: 'Beyond smarts, it is its conviviality. Beyond obedience or bossiness, it is an AniMate's relative autonomy and ability to share control.' Building on Illich's [42] notion of conviviality based on individual freedom and role swapping, Ackermann explores partial and shared control as critical quality of conviviality.

\subsubsection{Toward social intelligence}

Markopoulos et al. [89] identify four critical challenges to human computer interaction research for ambient intelligence components: 'Designing ambient intelligence systems and environments so that they can be perceived as socially intelligent ...Designing intelligence that will support human-to-human cooperation and social interactions... How to evaluate social intelligence? ...What are the benefits of social intelligence?'. The answer to the last question would appear to be a requirement for the evaluation of social intelligence and for designing intelligence that will support social interactions. Markopoulos et al. [89] experimenting with the iCat, a research platform that exhibits a rich set of human-like behaviors for studying social robotic user-interfaces, further state that for the ambient intelligence research community, the challenge ahead is 'the need to make systems capable of understanding and relating to people at a social level, timing, and cuing their interactions in a socially adept manner'. 
These are some of the challenges that social intelligence design aims to address with 'methods of establishing the social context, embodied conversational agents, collaboration design, public discourse, theoretical aspects of social intelligence design, and evaluation of social intelligence' [90]. As the pervasiveness of ambient intelligence increases, so does the need for social intelligence design, as a methodology to bring tools, like evaluation methods and measures, to better understand social concepts such as conviviality.

\subsection{Artificial companions and mixed-initiative interaction}

The companions that Wilks [91] envisions are persistent software agents attached to single users. They act as intermediaries for all information sources that users cannot manage. For instance, companions for seniors provide company to senior citizens who feel lonely; they act as technical task assistant to search the web for travels or keep track of events their owners forget. Conversely, companions for juniors provide assistance with teaching, explanations-on-demand and advice.

In a rather new area of research called mixed-initiative interaction 'people and computers take initiatives to contribute to solving a problem, achieving a goal, or coming to a joint understanding' [92]. A critical element is how users focus their attention: 'Attentional cues are central in decisions about when to initiate or to make an effective contribution to a conversation or project' [93]. Mixed-initiative research aims at developing software that filters appropriately incoming information to shield users from incoming disturbances such as emails and phone calls. The filtering of incoming information is achieved through measuring user's keystrokes and scrolling activities, recording the number of opened windows, analyzing content and checking events in calendars, location and time of day and also on psychological insights.

\subsubsection{The psychology of ambient intelligence}

In [37], a psychological framework for ambient intelligence is proposed, based on the concepts of action, situation and presence. A psychological definition of ambient intelligence, based on users' experience, is given as 'the effective and transparent support to the activity of the subject(s) through the use of information and communication technologies.' User activity is defined as the user's engagement toward a certain goal, while its effectiveness is the degree in which this activity reaches its goal. Guidelines are provided to support the work of ambient intelligence developers such as: an effective ambient intelligent system recognizes users' goals, the characteristics of the community they belong to and how to support the development of this community; it identifies the affordances and constraints of the situation users are in and the tools they need to mediate their activities.

The notion of presence often described as the sense of being there is defined by Riva as an evolved neuropsychological process that controls user activity. The feeling of presence provides feedback to users about the status of their activity, seeks to remedy breakdowns and to engage in optimal and rewarding activities and experiences. This conceptual framework calls for the development of self-adapting interfaces to allow ambient intelligence systems to automatically adapt to a particular end user behavior, activity level and social and cultural environment to achieve conviviality for each particular user. Support to these three kinds of awareness, user awareness, activity awareness and situation awareness, can be extended from individuals to groups and communities to attain convivial ambient intelligence environments.

\subsection{Conviviality as user experience for ambient intelligence scenarios}

The goal, to design interfaces that are closer to the way human think than the way machine operate, raises questions such as: 'What is, at this very moment, the user's state? What does s/he want, like, need, wish? Is s/he alone, at home, in family, with friends, at work?' [94]. In the context of such spontaneous interactions, innovative approaches based on dynamic notions such as conviviality, trust and behavior are required. Furthermore, in the area of the disappearing computer, 'the shift from information worlds to experience worlds' [95] is particularly significant. As stated by de Ruyter and Aarts [96], user experience for ambient intelligence must be based on: '(i) safeguarding the privacy of the home environment, (ii) minimizing the shift of user attention away from the actual content being consumed and (iii) creating the feeling of being connected when consuming content over different locations'.

From individual social assistants to communications facilitators, numerous research directions in HCI exemplify the interest for cognitive and social input to address issues as wide apart as information clutter and digital divide. We believe that conviviality can be an important concept to help address the broad challenges of ambient intelligence, by providing mechanisms for adaptive user interactions, while preserving the granularity of human experience.

\section{CONCLUSION}

Social concepts like service, contract and role are used in a variety of domains of computer science like software engineering, business informatics and MAS. The use of these concepts varies from abstract concepts in requirement analysis via formal concepts in conceptual modeling and measurable concepts in design to programming constructs. We argue in this paper that this list should be extended with a sociocognitive concept concerned with agent interaction which is used frequently in the social sciences, and has been discussed in applications of MAS where artificial and human agents interact like ambient intelligence, social intelligence design, 
digital cities and virtual communities. This concept is called conviviality.

In this paper we discuss the use of social concept 'conviviality' for computer science in general, and for the development of ambient technologies in particular. First, we give a survey of the use of the concept 'conviviality' in the social sciences. Conviviality is usually considered a positive concept related to sociability, however, further analysis reveals a negative side related to lack of diversity, privacy and ethical issues. Second, we argue that conviviality requirements for ambient intelligence are challenging, because ambient intelligence artifacts give rise to a new virtual and social reality, and conviviality issues play a central role in applications that are concerned with the interaction of material, virtual and social realities. Third, we propose a conviviality ontology by operationalizing the fuzzy concept of 'conviviality,' such that it can be used in computer science in the same way as other social concepts such as 'service,' 'contract' or 'trust' are used in this area. Conviviality is defined using dependence networks, and tools for conviviality are based on, what we call, conviviality masks. Fourth, we illustrate how convivial ambient intelligence applications can be designed using our operationalized concept of conviviality.

Ambient intelligence applications can greatly benefit from the positive aspects of conviviality: sharing knowledge and skills, dealing with conflict, enabling inclusiveness and encouraging equality and trust among parties. However, conviviality has first to be expressed explicitly and formalized before it can be used, efficiently, as a coordination mechanism between individuals, groups and institutions, and as a tool to reinforce social cohesion. There are several reasons to add conviviality as a sociol-cognitive concept to ambient intelligence systems models and theories.

(i) Requirements for ambient intelligence systems expressed by politicians and managers say that systems must be convivial, whereas system researchers and developers use other concepts.

(ii) When writing down requirements for user-friendly ambient intelligence systems, it is crucial to understand the inherent threads of conviviality.

(iii) The use of conviviality as an computer science concept ensures that considerations on the user-friendliness of ambient intelligence systems get the same importance and considerations on the functionality of the system.

(iv) It is a useful high-level modeling concept for organizations and communities, emphasizing the social side of them rather than the legal side.

(v) Fifth, the aim of social scientists is not to define the concept, but to create conviviality by creating the desired conditions for social interaction.

We illustrate our arguments and contributions with two main running examples on the use ambient technologies in digital cities, as prototypical examples where material reality such as ambient technologies interact with virtual and social realities. In the first example, a user arriving for the first time in a new city is able to find her way and feel at ease, thanks to her mobile phone digital assistant and thanks to the digital notes left by other users in the digital city. In the second example, a user is driven to the city, by his car digital assistant, and seamlessly meets his friends in virtual spaces and in real physical spaces.

We consider the following topics as most important for further research:

Conviviality measures. Conviviality is important for software systems design involving human actors, and to use conviviality effectively we need to measure it. Therefore, we analyzed its effects to allow us to adjust systems to be more adapted to users' needs. This is particularly relevant in a modern context because of the pervasive development of digital cities.

Dynamic dependence networks. The extension of dependence networks with preferences on goals and dynamics.

Normative systems for conviviality masks. Mechanism for conviviality masks.

\section{ACKNOWLEDGEMENT}

We thank the reviewers of this journal for useful suggestions.

\section{FUNDING}

We thank the City of Luxembourg for their financial support.

\section{REFERENCES}

[1] Weyrich, C. (1999) Orientations for Workprogramme 2000 and Beyond. Information Society Technologies Report. Information Society Technologies Advisory Group.

[2] Kameas, A. and Mavrommati, I. (2005) Extrovert gadgets. Commun. ACM, 48, 69.

[3] Lahlou, S., Langheinrich, M. and Roecker, C. (2005) Privacy and trust issues with invisible computers. Commun. ACM, 48, 59-60.

[4] Streitz, N. and Nixon, P. (2005) Introduction. Commun. ACM, 48, 32-35.

[5] Coutaz, J., Crowley, J.L., Dobson, S. and Garlan, D. (2005) Context is key. Commun. ACM, 48, 49-53.

[6] Caire, P. (2009) Designing convivial digital cities: a social design intelligence approach. AI Society, 24, 97.

[7] Caire, P. (2009) How to import the concept of conviviality to web communities. Int. J. Web Based Commun., to appear.

[8] Maier, M.W., Emery, D. and Hilliard, R. (2004) Ansiieee 1471 and systems engineering. Syst. Eng., 7, 257-270.

[9] Burrows, M., Abadi, M. and Needham, R.M. (1989) A Logic of Authentication. Proc. 12th ACM Symp. Operating Systems Principles, pp. 1-13. ACM, New York. 
[10] Bohn, J., Coroama, V., Langheinrich, M., Mattern, F. and Rohs, M. (2005) Social, Economic, and Ethical Implications of Ambient Intelligence and Ubiquitous Computing. In Weber, W., Rabaey, J., and Aarts, E. (eds), Ambient Intelligence, pp. 5-29. Springer.

[11] Bryce, C., Dekker, M., Etalle, S., Le Métayer, D., Le Mouël, F., Minier, M., Moret-Bailly, J. and Ubéda, S. (2007) Ubiquitous Privacy Protection. Proc. 5th Workshop on Ubicomp Privacy in Conjunction with the 9th Int. Conf. on Ubiquitous Computing (UbiComp'2007), Innsbruck, Austria, September, Position Paper.

[12] Boella, G., Sauro, L. and van der Torre, L.W.N. (2004) Social Viewpoints on Multiagent Systems. Autonomous Agents and Multi-Agent Systems (AAMAS), pp. 1358-1359. IEEE Computer Society.

[13] Parikh, R. (2002) Social software. Synthese, 132, 187-211.

[14] Castelfranchi, C. (1998) Modeling social action for AI agents. Artif. Intell., 103, 157-182.

[15] Castelfranchi, C. (2003) The micro-macro constitution of power. Protosociology, 18, 208-269.

[16] Meyer, B. (2001) At the Edge of Design by Contract. In TOOLS: 38th Int. Conf. Technology of Object-Oriented Languages and Systems, Components for Mobile Computing, Zurich, Switzerland, 12-14 March 2001, 3pp. IEEE Computer Society.

[17] Meyer, B. (1993) Systematic Concurrent Object-Oriented Programming. In Ege, R.K., Singh, M.S. and Meyer, B. (eds), TOOLS: 11th Int. Conf. Technology of Object-Oriented Languages and Systems, Components for Mobile Computing, Zurich, Switzerland, 12-14 March 2001, 553pp. Prentice-Hall.

[18] Meyer, B. (2001) TOOLS Europe 2001: 38th Int. Conf. Technology of Object-Oriented Languages and Systems, Components for Mobile Computing, Zurich, Switzerland, 12-14 March 2001. IEEE Computer Society.

[19] Alchourrón, C. (1993) Philosophical Foundations of Deontic Logic and the Logic of Defeasible Conditionals. In Meyer, J.-J. and Wieringa, R. (eds), Deontic Logic in Computer Science: Normative System Specification, pp. 43-84. John Wiley \& Sons.

[20] Jin, J. and Nahrstedt, K. (2008) Qos-aware service management for component-based distributed applications. ACM Trans. Internet Technol., 8, 1-31.

[21] Nahrstedt, K. (2008) Need for Integrated Quality of Service and Quality of Protection in Mobile Systems. In Nikoletseas, S.E., Abu-Ghazaleh, N.B., Bensaou, B. and Syrotiuk, V.R. (eds), MSWiM, Vol. 148. ACM.

[22] Gu, X. and Nahrstedt, K. (2006) Distributed multimedia service composition with statistical QoS assurances. IEEE Trans. Multimedia, 8, 141-151.

[23] Malone, T.W. and Crowston, K. (1994) The interdisciplinary study of coordination. ACM Comput. Surv., 26, 87-119.

[24] Jennings, N.R. (2000) On agent-based software engineering. Artif. Intell., 117, 277-296.

[25] Lesser, V.R. (1998) Reflections on the nature of multi-agent coordination and its implications for an agent architecture. Auton. Agents Multi-Agent Syst., 1, 89-111.

[26] Nwana, H.S. and Heath, M. (1996) Software agents: an overview. Knowl. Eng. Rev., to appear.

[27] Martial, F.V. (1992) Coordinating Plans of Autonomous Agents. Springer, New York.
[28] Arbab, F. (1998) Coordination and Its Relevance. DEXA Workshop, pp. 529-535.

[29] den Besselaar, P.V., Melis, I. and Beckers, D. (2000) Digital cities: organization, content, and use. In Ishida, T. and Isbister, K. (eds), Digital Cities, Technologies, Experiences, and Future Perspectives, Lecture Notes in Computer Science, Vol. 1765, pp. 18-32. Springer.

[30] Azechi, S., Fujihara, N., Sumi, K., Hirata, T., Yano, H. and Nishida, T. (2000) Public opinion channel: A challenge for interactive community broadcasting. In Ishida, T. and Isbister, K. (eds), Digital Cities, Technologies, Experiences, and Future Perspectives, Lecture Notes in Computer Science, Vol. 1765, pp. 427-441. Springer.

[31] Ishida, T. (2000) Understanding digital cities. In Ishida, T. and Isbister, K. (eds), Digital Cities, Technologies, Experiences, and Future Perspectives, Lecture Notes in Computer Science, Vol. 1765, pp. 7-17. Springer.

[32] Tanabe, M., den Besselaar, P.V. and Ishida, T. (eds) (2002) Digital Cities II, Computational and Sociological Approaches, Second Kyoto Workshop on Digital Cities, Kyoto, Japan, 18-20 October 2001, Revised Papers, Lecture Notes in Computer Science, 2362. Springer.

[33] Ishida, T. and Isbister, K. (eds) (2000) Digital Cities, Technologies, Experiences, and Future Perspectives. Lecture Notes in Computer Science, Vol. 1765. Springer (the book is based on an Int. Symp., Kyoto, Japan, September 1999).

[34] Caire, P. (2007) Designing Convivial Digital Cities. In A. Nijholt, O. S. and Nishida, T. (eds), Proc. 6th Workshop on Social Intelligence Design (SID'07), pp. 25-40.

[35] Boella, G., van der Torre, L. and Villata, S. (2008) Institutional Social Networks for Ambient Intelligence. AISB 2008 Convention: Communication, Interaction and Social Intelligence.

[36] Rheingold, H. (1991) Virtual Reality. Simon \& Schuster, Inc., New York, NY, USA.

[37] Riva, G., Vatalaro, F., Davide, F. and Alcaniz, M. (2005) Ambient Intelligence. IOS Press.

[38] Searle, J. (1995) The Construction of Social Reality. The Free Press, New York.

[39] Ackermann, E.K. (2005) Playthings that do things: a young kid's “incredibles"! IDC '05: Proc. 2005 Conf. Interaction Design and Children, New York, NY, USA, pp. 1-8. ACM.

[40] Sipitakiat, A. (2001) Digital technology for conviviality: making the most of students' energy and imagination in learning environments. Master's Thesis. MIT, Cambridge, MA, USA.

[41] Schechter, M. (2004) Conviviality, gender and love stories: Plato's symposium and ISAK Dinesen's (K. Blixen's) Babette's feast. Trans: Internet J. Cultural Sci., 1.

[42] Illich, I. (1974) Tools for Conviviality. Marion Boyars Publishers.

[43] Sadek, M. D., Bretier, P. and Panaget, E. (1997) ARTIMIS: Natural Dialogue Meets Rational Agency. Int. Joint Conf. Artificial Intelligence (2), pp. 1030-1035.

[44] Taylor, M. (2004) Oh no it isn't: Audience participation and community identity. Trans: Internet J. Cultural Sci., 1.

[45] Academie-Francaise (2000) Dictionnaire de l'Academie Francaise. Academie Francaise.

[46] Oxford-Dictionary (2007) Oxford English Dictionary. Oxford University Press. 
[47] Dictionnaire-Terminologique (2007) Le Grand Dictionnaire Terminologique. Office Quebecois de la Langue Francaise.

[48] Polanyi, M. (1958) Personal Knowledge: Towards a Post-Critical Philosophy. Routledge \& Kegan Paul Ltd, London.

[49] Polanyi, M. (1974) Personal Knowledge: Towards a Post-Critical Philosophy. University of Chicago Press.

[50] Illich, I. (1971) Deschooling Society. Marion Boyars Publishers Ltd.

[51] Putnam, R.D. (1988) Diplomacy and domestic politics: the logic of two-level games. Int. Organ., 42, 427-460.

[52] Putnam, R.D. (2000) Bowling alone: the collapse and revival of American community. Comput. Support. Coop.Work, p. 357.

[53] Papert, S. and Harel, I. (1991) Constructionism. MIT Press, Cambridge, MA.

[54] Shehory, O. and Kraus, S. (1998) Methods for task allocation via agent coalition formation. Artif. Intell., 101, 165-200.

[55] Shoham, Y. and Leyton-Brown, K. (2008) Multiagent Systems: Algorithmic, Game-Theoretic, and Logical Foundations. Cambridge University Press, New York.

[56] Ashby, W. (2004) Unmasking narrative: A semiotic perspective on the conviviality/non-conviviality dichotomy in storytelling about the german other. Trans: Internet J. Cultural Sci., 1.

[57] Malone, T.W. et al. (1999) Tools for inventing organizations: Toward a handbook of organizational processes. Manage. Sci., 45, 425-443.

[58] Wright, D. (2005) The dark side of ambient intelligence. J. Policy, Regul. Strategy Telecommun., 7, 33-51.

[59] Lomosits, H. (2004) Future is not a tense. Trans: Internet J. Cultural Sci., 1.

[60] Hofkirchner, W. (2004) Unity through diversity dialecticssystems thinking—semiotics. Trans: Internet J. Cultural Sci., 1.

[61] Somov, G.Y. (2004) Conviviality problems in the structure of semiotic objects. Trans: Internet J. Cultural Sci., 1.

[62] Persson, P. and Espinoza, F. (2001) Geonotes: social enhancement of physical space. ERCIM News, Ambient Intelligence, p. 29.

[63] Couderc, P. (2006) Collaborative capture: a new perspective for sensor networks. ERCIM News, Embedded Intelligence, p. 42.

[64] Stephanidis, C. (2006) A European ambient intelligence research facility at ICS-forth. ERCIM News, Embedded Intelligence, p. 31.

[65] Bourdon, X.L., Couderc, P. and Banatre, M. (2006) Spontaneous hotspots: Sharing Context-Dependant Resources Using Bluetooth. ICAS '06: Proc. Int. Conf. Autonomic and Autonomous Systems, Washington, DC, USA, 42pp. IEEE Computer Society.

[66] Cheng, W., Li, J., Moore, K. and Karp, A.H. (2007) Muppet: Mobile Ubiquitous Privacy Protection for Electronic Transactions. Information Society Technologies Report. Hewlett Packard Laboratory.

[67] Langheinrich, M. (2005) Personal privacy in ubiquitous computing - tools and system support. PhD Thesis, ETH Zurich, Switzerland.

[68] Sichman, J.S. and Conte, R. (2002) Multi-Agent dependence by Dependence Graphs. Autonomous Agents and Multi-Agent Systems (AAMAS), pp. 483-490. ACM.

[69] Boella, G., Sauro, L. and van der Torre, L.W.N. (2007) From social power to social importance. Web Intell. Agent Syst., 5, 393-404.
[70] Caire, P., Villata, S., Boella, G. and van der Torre, L. (2008) Conviviality Masks in Multiagent Systems. In Padgham, L., Parkes, D.C., Müller, J. and Parsons, S. (eds), Autonomous Agents and Multi-Agent Systems (AAMAS), Vol. 3, pp. 1265-1268. IFAAMAS.

[71] Wooldridge, M. (2004) An introduction to multi-agent systems. J. Artifi. Soc. Social Simul., 7, 16-23.

[72] Boella, G., van der Torre, L. and Verhagen, H. (2006) Introduction to normative multiagent systems. Comput. Math. Organ. Theory, 12, 71-79.

[73] Boella, G., Damiano, R., Hulstijn, J. and van der Torre, L. (2007) A common ontology of agent communication languages: Modeling mental attitudes and social commitments using roles. Appl. Ontol., 2, 217-265.

[74] Yu, E. (1995) Modelling strategic relationships for process reengineering. PhD Thesis, University of Toronto, Canada.

[75] Bresciani, P., Perini, A., Giorgini, P., Giunchiglia, F. and Mylopoulos, J. (2004) Tropos: an agent-oriented software development methodology. Auton. Agents Multi-Agent Syst., 8, 203-236.

[76] Caire, P. A normative multi-agent systems approach to the use of conviviality for digital cities. In Noriega, P. and Padget, J. (eds), Proc. Int. Workshop on Coordination, Organization, Institutions and Norms in Agent Systems (COIN), Durham, UK, pp. 15-26.

[77] Gomes, E.R., Boff, E. and Vicari, R.M. (2004) Social, Affective and Pedagogical Agents for the Recommendation of Student Tutors. Proc. Intelligent Tutoring Systems.

[78] Seidl, R., Berger, F., Kapellaki, S., Frantti, T., Rukzio, E., Hamard, J. and Melazzi, N.B. (2004) The Simplicity Project: Personalized and Simplified Communication Spaces for Mobile Users. IST Mobile and Wireless Communications Summit 2004, Lyon, France, 5pp. Information Society Technologies.

[79] Erickson, T. and Kellogg, W.A. (2000) Social translucence: an approach to designing systems that support social processes. ACM Trans. Comput.-Hum. Interact., 7, 59-83.

[80] Lahlou, S. and Jegou, F. (2003) European Disappearing Computer Privacy Design Guidelines v1.0. Ambient Agoras Report d15.4. Disappearing Computer Initiative.

[81] Ochs, M., Niewiadomski, R., Pelachaud, C. and Sadek, D. (2005) Intelligent Expressions of Emotions. In Tao, J., Tan, T. and Picard, R. W. (eds.), Affective Computing and Intelligent Interaction, Lecture Notes in Computer Science, Vol. 3784, pp. 707-714. Springer.

[82] Merriam-Webster, I. (2006) Merriam Webster OnLine Dictionary. Merriam-Webster.

[83] Casare, S. and Sichman, J. (2005) Towards a Functional Ontology of Reputation. AAMAS '05: Proc. Fourth Int. Joint Conf. Autonomous Agents Multiagent Systems, New York, NY, USA, pp. 505-511. ACM.

[84] Caire, P. (2007) A Critical Discussion on the Use of the Notion of Conviviality for Digital Cities. Proc. Web Communities 2007, Salamanca, Spain, pp. 193-200.

[85] Lau, G.T., Law, K.H. and Wiederhold, G. (2005) Analyzing government regulations using structural and domain information. IEEE Comput., 38, 70-76.

[86] Boella, G. and van der Torre, L.W.N. (2004) Regulative and Constitutive Norms in Normative Multiagent Systems. In 
Dubois, D., Welty, C.A. and Williams, M.A. (eds), Knowledge Representation, pp. 255-266. AAAI Press.

[87] Lawrence, D.G. (1976) Procedural norms and tolerance: A reassessment. Amer. Political Sci. Rev., 70, 80-100.

[88] Lamizet, B. (2004) Culture-commonness of the common? Trans: Internet J. Cultural Sci., 1.

[89] Markopoulos, P., de Ruyter, B., Privender, S. and van Breemen, A. (2005) Case study: bringing social intelligence into home dialogue systems. Interactions, 12, 37-44.

[90] Nishida, T. (2001) Social Intelligence Design-An Overview. In Terano, T., Nishida, T., Namatame, A., Tsumoto, S., Ohsawa, Y. and Washio, T. (eds), JSAI Workshops, Lecture Notes in Computer Science, Vol. 2253, pp. 3-10. Springer.

[91] Wilks, Y. (2004) Artificial Companions. In Bengio, S. and Bourlard, H. (eds), Machine Learning for Multimodal Interaction, Lecture Notes in Computer Science, Vol. 3361, pp. 36-45. Springer.
[92] Horvitz, E., Koch, P. and Apacible, J. (2004) Busybody: Creating and Fielding Personalized Models of the Cost of Interruption. In Herbsleb, J.D. and Olson, G.M. (eds), Computer Supported Cooperative Work, pp. 507-510. ACM.

[93] Horvitz, E., Kadie, C.M., Paek, T. and Hovel, D. (2003) Models of attention in computing and communication: from principles to applications. Commun. ACM, 46, 52-59.

[94] Gross, T. (2001) Ambient interfaces for distributed work groups. ERCIM News, Ambient Intelligence.

[95] Streitz, N., Magerkurth, C., Prante, T. and Roecker, C. (2005) From information design to experience design: smart artefacts and the disappearing computer. Interactions, 12, 21-25.

[96] de Ruyter, B. and Aarts, E. (2004) Ambient Intelligence: Visualizing the Future. AVI '04: Proc. Working Conf. Advanced Visual Interfaces, New York, NY, USA, pp. 203-208. ACM. 